NBER WORKING PAPER SERIES

\title{
INFORMATION, ANIMAL SPIRITS, AND THE MEANING OF INNOVATIONS IN CONSUMER CONFIDENCE
}

\author{
Robert B. Barsky \\ Eric R. Sims \\ Working Paper 15049 \\ http://www.nber.org/papers/w15049
NATIONAL BUREAU OF ECONOMIC RESEARCH
1050 Massachusetts Avenue
Cambridge, MA 02138
June 2009

The authors gratefully acknowledge helpful comments and suggestions from Susanto Basu, Alan Blinder, John Cochrane, Olivier Coibion, Daniel Cooper, Mike Elsby, Yuriy Gorodinchenko, Christopher House, Peter Ireland, Lutz Kilian, Miles Kimball, Guido Lorenzoni, Serena Ng, Matthew Shapiro, Robert Solow, Frank Vella, two anonymous referees, and seminar participants at Boston College, Johns Hopkins, Michigan, the Wharton School, the Russell Sage Foundation, and the NBER Summer Institute in Monetary Economics. We also thank John Fernald for providing his quarterly utilization-corrected TFP measure. Robert Barsky acknowledges generous support as a visiting scholar at the Russell Sage Foundation and the Bank of Israel. The views expressed herein are those of the author(s) and do not necessarily reflect the views of the National Bureau of Economic Research.

NBER working papers are circulated for discussion and comment purposes. They have not been peerreviewed or been subject to the review by the NBER Board of Directors that accompanies official NBER publications.

(C) 2009 by Robert B. Barsky and Eric R. Sims. All rights reserved. Short sections of text, not to exceed two paragraphs, may be quoted without explicit permission provided that full credit, including $\odot$ notice, is given to the source. 
Information, Animal Spirits, and the Meaning of Innovations in Consumer Confidence Robert B. Barsky and Eric R. Sims

NBER Working Paper No. 15049

June 2009, Revised August 2010

JEL No. E2,E3,E32

\begin{abstract}
$\underline{\text { ABSTRACT }}$
Innovations to measures of consumer confidence convey incremental information about economic activity far into the future. Comparing the shapes of impulse responses to confidence innovations in the data with the predictions of a calibrated New Keynesian model, we find little evidence of a strong causal channel from autonomous movements in sentiment to economic outcomes (the "animal spirits" interpretation). Rather, these impulse responses support an alternative hypothesis that the surprise movements in confidence reflect information about future economic prospects (the "information" view). Confidence innovations are best characterized as noisy measures of changes in expected productivity growth over a relatively long horizon.
\end{abstract}

Robert B. Barsky

Department of Economics

University of Michigan

Ann Arbor, MI 48109-1220

and NBER

barsky@umich.edu

Eric R. Sims

University of Notre Dame

ericsims@umich.edu 


\section{Introduction}

In the popular press and much of the business community it continues to be an article of faith that "consumer confidence" has an important role - both prognostic and causal - in macroeconomics. On the other hand, the stance of the rather limited academic literature on confidence is far more ambiguous. The judgments range from the conclusion that confidence measures have an important role both in prediction and in understanding the causes of business cycles, to the view that they contain important information but have little causal role, to the verdict that they have no value even in forecasting.

There are, broadly speaking, two contrasting approaches to the role of confidence in macroeconomics. The first, which we will refer to as the "animal spirits" view, posits autonomous fluctuations in beliefs that in turn have causal effects on economic activity. In the proceedings of a symposium on the causes of the 1990-1991 recession, both Hall (1993) and Blanchard (1993) regard exogenous movements in consumption as a cause of business cycles. Indeed, Blanchard proposes that the cause of the recession was a powerful, long-lasting negative consumption shock associated with an exogenous shift in pessimism that had a causal effect on overall aggregate demand. While not fully pursuing the idea in his brief paper, Blanchard proposes that one might be able to test this hypothesis on the basis of the observation that such an exogenous shift in pessimism ought to have only temporary effects on consumption. ${ }^{1}$

The second view of confidence - what we will call the information or news view - suggests that a relationship between innovations in measures of consumer confidence and subsequent macroeconomic activity arises because confidence measures contain fundamental information about the current and future states of the economy. For example, Cochrane (1994b) proposes that consumption surprises proxy for news that consumers receive about future productivity that does not otherwise show up in econometricians' information sets. His attempt to reconcile VAR evidence with theory closely anticipates the "news" approach to business cycles of Beaudry and Portier (2004, 2006). They analyze models where agents become aware of changes in future productivity orthogonal to current productivity. The information or "news" view of confidence supposes that confidence innovations might contain similar information.

In Section 2, we show that unexplained movements in responses to forward-looking questions from the Michigan Survey of Consumers have powerful predictive implications for the future paths of macroeconomic variables. In the context of trivariate VARs, the impulse responses of consumption and income to innovations in consumer confidence measures are significant, slowly buidling, and apparently permanent. Confidence is not Granger-caused by income or consumption, nor are its innovations highly correlated with innovations in those variables. These

\footnotetext{
${ }^{1}$ In some ways, a limiting case of animal spirits appears in the "sunspot" literature. Though pinned down only by extrinsic coordinating variables, expectations in the equilibria of these models are self-fulfilling, and thus rational. (see Farmer (1999)). The existence of sunspot equilibria depend on strong increasing returns, supply externalities, or other mechanisms that are typically not accepted as empirically plausible. The notion of animal spirits in this paper does not encompass sunspots.
} 
observations point to the conclusion that our measures of consumer confidence are not merely noise, nor are they simply reflections of information contained in other variables with which they are correlated. The fact that confidence innovations have implications for consumption and income many periods in the future suggests that there is at least some truth to the news view of confidence. Permanent movements in consumption and income must reflect corresponding movements in technology, which is putatively unaffected by animal spirits. If confidence contained no news about future fundamentals and the relationship between confidence and subsequent activity reflected only animal spirits effects, one would expect to see at most transitory responses of consumption and income to confidence innovations. ${ }^{2}$

In Sections 3 and 4 - the heart of the paper - we attempt to gauge the extent to which these impulse responses indicate a causal channel from sentiment to economic outcomes (the animal spirits view), as opposed to the alternative scenario under which the surprise confidence movements summarize news about economic prospects received by consumers (the news view). To provide a framework for distinguishing these alternative interpretations of confidence, we present in Section 3 a relatively standard New Keynesian DSGE model with two main shocks of interest. ${ }^{3}$ The first is a reflection of genuine news that productivity will grow more rapidly for a substantial period of time into the future (the "news shock"). The second shock, inspired by Lorenzoni (2009), arises because we permit households to observe only a noise-ridden signal of the news shock. We interpret the noise as an "animal spirits shock", as it is associated with optimism or pessimism that - while not ex ante irrational - is erroneous from the point of view of an outside observer with knowledge of the shocks. A series of positive animal spirits shocks might capture the possibility that periods such as the 1920s or 1990s were fueled by optimism not warranted by fundamentals, while a predominance of negative shocks would usher in a period of excessive pessimism. We model confidence as a composite signal reflecting both fundamentals and noise, so that confidence innovations are a linear combination of the structural shocks in the model.

In the model, animal spirits shocks are associated with transitory changes in consumption and income that attenuate over time. News shocks about future productivity are followed by gradual movements in the macroeconomic variables that are not subsequently reversed. Because the theoretical response to an animal spirits shock is reverting while the theoretical response to a news shock is not, it appears at first blush that one might successfully distinguish animal spirits shocks from news shocks using a structural VAR with a long-run restriction. Blanchard, Lorenzoni, and L'Hullier(2009) indicate that this is not likely to be the case. These authors

\footnotetext{
${ }^{2}$ This is not to say that a long-run restriction in a VAR context allows us to disentangle information and animal spirits effects when both are present. See below.

${ }^{3}$ Because of the assumed frictions in the model (price stickiness, habit formation, and adjustment costs), there exist parameter configurations in which news and animal spirits can induce business cycle-like fluctuations. The model is thus not necessarily subject to the co-movement "problem" highlighted by Beaudry and Portier (2004) and Jaimovich and Rebelo (2008).
} 
show, in the context of a model somewhat simpler than ours but incorporating essentially the same signal extraction problem, that a structural VAR is unable to recover the shocks from the model. ${ }^{4}$ Thus we need to use an alternative method to identify the shocks and disentangle the information component of confidence from the animal spirits component.

We begin Section 4 by estimating an expanded VAR with the variables implied by the model augmented with a measure of confidence. As in the three variable systems of Section 2, the results show that confidence innovations are associated with little immediate response of real activity but prolonged subsequent growth in consumption and income. Positive confidence innovations are associated with a substantial drop in inflation, and - importantly - a marked increase in real interest rates. Next, by minimizing the distance between these empirical impulse responses and those generated from simulations of the model (and making use of some additional information about moments of the data), we estimate the deep parameters of the model via indirect inference. This allows us to compute impulse responses to the true structural shocks, variance decompositions of confidence and the other variables in the model, and - using the Kalman smoother - approximate historical decompositions.

The results are unambiguous. At the estimated parameters, while animal spirits and pure noise (e.g. measurement error in confidence) together account for about half the innovation variance in confidence, animal spirits effects are very weak and thus account for essentially none of the relationship between confidence and future consumption or income. In a revealing counterfactual exercise, we repeat the simulation of the model - this time imposing parameters that are intended not to match the data but to maximize the causal effect of animal spirits on subsequent activity. Estimating the VAR on these simulated data, we find that the impulse responses look very different from the empirical impulse responses. Strong animal spirits effects imply that confidence innovations are associated with much stronger initial jumps in consumption and income than in the data. The parameters favoring large animal spirits effects also fail to deliver the fall in inflation and rise in real interest rates in response to a confidence innovation that are striking features of the empirical impulse responses.

We are able to reject the hypothesis that animal spirits shocks (as specified in this paper) are an important source of the observed relationships between confidence innovations and macroeconomic variables. On the other hand, we find convincing evidence in favor of the information interpretation of confidence. Though the implications of confidence innovations for

\footnotetext{
${ }^{4}$ One way of thinking about this is as follows. An expectation on the part of consumers that their consumption would decline over time following a period of high confidence would be tantamount to an awareness on the part of these agents that they were in the grip of animal spirits. This would be incompatible with the maintained hypothesis of optimization, including rational signal extraction. Because in the VAR framework consumers and the econometrician form the same expectations as a function of lagged variables, if the econometrician could compute an impulse response that implies reverting behavior of consumption, so could the consumer. This argument indicates that the econometrician cannot recover the animal spirits shock by inverting the VAR, but leaves open the possibility that the econometrician can uncover the underlying shocks and their impulse response functions by estimating the model.
} 
output and spending at short horizons are far too small for confidence to be primarily a reflection of changes in current fundamentals, the longer horizon implications are far too large and significant for confidence innovations not to be conveying information about future fundamentals. Our results suggest that there are news shocks about future productivity not wholly reflected in current productivity, and that these shocks account for a significant fraction of the innovation in measured confidence, as well as the lion's share of the nexus from confidence to future activity.

In Section 5, we ask the question "What exactly is this news that agents are receiving?" Responses to little-used survey questions on "news heard" do help somewhat to explain confidence innovations, but with only a very modest incremental $R^{2}$. The news accounting for innovations in our confidence measures is apparently not primarily tangible macroeconomic or other national news. Rather, we conclude, confidence data aggregate many pieces of disparate information in the hands of various consumers.

Section 6 contains a brief summary and conclusions.

\section{Confidence and Forecasts of Economic Activity}

How does a surprise movement in confidence affect our forecasts of future income and consumption? A standard first pass at answering this question is to run a VAR with consumption, income and a measure of confidence, and to consider the partial derivatives of consumption and income at various horizons with respect to innovations in the confidence variable. These can be thought of in terms of the generalized impulse response function of Pesaran and Shin (1998). Though the result coincides with that from a recursive system with the confidence variable ordered first, it is important to stress that we are not setting up a structural VAR model. At this point, we interpret impulse response functions not as dynamic responses to structural shocks but in terms of the displacement of forecasts implied by unexpected movements in confidence.

Ultimately, of course, we are not primarily interested in forecasting. Generalized impulse response functions have been criticized because they do not correspond to the causal dynamic responses from any "identified" model. Although this exercise may appear unguided by theory at this point, its full justification will come in the next section where - in the spirit of indirect inference - we compare the results from an empirical VAR to those arising from application of the same VAR specification to data generated from a structural DSGE model with news and animal spirits shocks.

One might also want to know whether confidence has incremental effects on forecasts of future activity once we account for the current innovations in consumption and income. That would suggest considering the impulse response to a confidence innovation ordered last in a recursive system. Note that when we do orthogonalize the shocks we decline to take a position on which orthogonalization is the "true" one. Because we consider only the responses to E5Y innovations, ordered either first or last, we never have to choose an ordering between consumption and income. Once again, our concern at the moment is with the extent to which confidence innovations alter 
our forecasts of future activity.

\subsection{Confidence Data}

The survey measure that we will make the most use of in this paper, which we call E5Y, summarizes responses to the following question: "Turning to economic conditions in the country as a whole, do you expect that over the next five years we will have mostly good times, or periods of widespread unemployment and depression, or what?" The variable is constructed as the percentage giving a favorable answer minus the percentage giving an unfavorable answer plus one hundred. ${ }^{5}$ Our particular affinity for this question arises from the fact that it is aimed at gauging expectations over a relatively long horizon, and because of its specificity as to the relevant time frame. ${ }^{6}$ However, its correlation with the responses to a similar question specifying a horizon of only twelve months (a variable we call E12M) is 91 percent, and its correlation with another concerning expected changes in personal financial situation over the next twelve months is 85 percent. The correlation of E5Y with the overall expectations component of the Michigan index exceeds 95 percent. Our results in this section are essentially unchanged by the substitution of either of these alternative expectations variables.

Figure 1 plots E5Y and E12M against time. Both series undergo repeated dramatic swings though (as we would expect) the twelve-month-ahead expectations are more volatile than those with a five year horizon. Both variables are persistent yet are, as clearly indicated by standard tests, stationary. The cross-correlogram between E5Y and the conventional Hodrick-Prescott detrended GDP (not shown) indicates that the expectations are by no means a reflection of current output; the contemporaneous correlation between detrended GDP and E5Y is essentially zero. E5Y is negatively correlated with the output gap lagged several periods, and positively correlated with the gap several quarters ahead.

\subsection{Three Variable VAR}

We include real GDP, real consumption of goods and services, and E5Y in a VAR system with four lags. ${ }^{7}$ We estimate the system in the levels of the variables. Our results are nearly identical when imposing a cointegrating relationship between consumption and income. We show the impulse responses to a confidence innovation with E5Y ordered first in Figure 2. The shaded areas represent one standard error percent bias-corrected bootstrap confidence bands of Kilian (1998).

\footnotetext{
${ }^{5}$ Thus a value of 100 is a "neutral" position, while a value of 140 means that the fraction of responses reflecting optimism about the future exceeds the fraction reflecting pessimism by forty percentage points.

${ }^{6}$ Some might argue as well that this question gives the animal spirits hypothesis its "best shot". One argument is that individuals are likely to be more sober-minded in assessing family resources than in forming expectations about the national economy. Another is based on animal spirits models that focus on strategic complementary; in those models beliefs about the economic activities of other agents are central.

${ }^{7}$ The data on GDP and consumption come from the BEA's NIPA accouts. The sample period runs 1960:12008:4.
} 
An innovation to E5Y has very small implications for both consumption and output on impact. The small impact effects are followed by slowly-building, significant, and apparently permanent responses of both consumption and output. A one standard deviation innovation to E5Y predicts levels of output and consumption that are roughly 0.6 percent higher forty quarters hence; further, the long run responses of both consumption and GDP to an E5Y innovation are statistically significant at better than the 95 percent level. E5Y innovations thus rather clearly convey important information about the future time paths of real activity variables, most notably at longer horizons.

To what extent, however, are innovations in E5Y simply reflective of information already contained in consumption and income innovations? To address this possibility, we re-order the variables in the system such that E5Y is orthogonalized with respect to income and consumption. Figure 3 presents impulse responses with this ordering. The qualitative features of the impulse responses are unaffected by the alternative orthogonalization. In particular, E5Y innovations still predict slowly-building and permanent responses of both output and consumption. The point estimates are slightly smaller than in the case with E5Y ordered first, with a one standard deviation innovation to E5Y prognostic of long run increases in both consumption and output of slightly more than 0.5 percent (as opposed to 0.6 percent with E5Y ordered first).

Figure 4 graphically depicts the fraction of the variance of consumption, income, and E5Y accounted for by E5Y innovations under both orthogonalizations. Ordered first, E5Y innovations account for more than half of the forecast error variance of income and consumption at long horizons. Even after orthogonalization with respect to consumption and income, innovations to E5Y still account for more than 30 percent of the long horizon forecast error variance of both income and consumption. We can thus easily reject the hypothesis that E5Y simply reflects information available in income and consumption innovations. The fact that the qualitative results hold regardless of whether or not E5Y is first orthogonalized with respect to consumption indicate that the shape of the impulse responses is due heavily to Granger causality from E5Y to both consumption and output. Reduced form innovations in income, consumption and confidence are significantly, though rather modestly, mutually correlated. E5Y is not Granger-caused by income or consumption and responds mostly to its own innovation.

We now examine several variations on the three variable VAR using alternative measures of consumer confidence. First, we substitute the relative score from the question on the Michigan Survey concerning expected personal financial situation (PFE) in place of E5Y. This question gauges expectations analogously to E5Y and E12M, although it specifically asks for expectations concerning personal situations as opposed to aggregate expectations. ${ }^{8}$ The second

\footnotetext{
${ }^{8}$ Dominitz and Manksi (2004) express doubt that consumers can give meaningful responses to survey questions concerning aggregate as opposed to individual expectations, and they point to the higher volatility of responses to questions like E5Y versus questions like PFE as support. Given the structure of the questions, however, we would in fact expect aggregate questions to have greater volatility even if individuals are equally capable of answering both kinds of questions accurately. For example, even in severe recessions most people do not
} 
modification is to use the Index of Consumer Sentiment (ICS) in place of the purely forwardlooking survey questions. While the ICS is the most reported measure of consumer confidence (both by the press and in the academic literature), it is an average of survey responses to both forward-looking and retrospective questions, and thus its interpretation is unclear. For a more detailed description of these alternative confidence measures and their statistical relationships with E5Y, please contact the authors, or visit the Michigan Survey of Consumers website (http://www.sca.isr.umich.edu/).

Figure 5 presents impulse responses to confidence innovations in our three variable system with three alternative measures of confidence: E5Y, PFE, and ICS. There is very little qualitative or quantitative difference between the results using E5Y or any of the other broad confidence measures. Use of other alternative confidence measures such as E12M or the expectations component of the survey also makes little difference. Any disparity between our results and others in the literature is due to something other than the measure of confidence chosen. ${ }^{9}$ Alternative measures of consumption and output (for example, durable goods consumption or private sector GDP) also produce very similar impulse responses. In summary, innovations in expectational variables from the Michigan Survey of Consumers have slowly-building, longlasting implications for future consumption and output.

\subsection{Relation to Cochrane (1994a, 1994b) and Carroll, Fuhrer, and Wilcox (1994)}

Cochrane (1994a) estimates two-variable VARs with consumption and income. His principal result is that innovations in consumption are associated with large subsequent movements in income that swamp the response of income to its own innovation, at least at longer horizons. At the shorter horizons, most of the movement in income is explained by its own innovation, but the "effects" of a consumption innovation build over time so that much or all of the permanent component of GDP appears to be captured by innovations in consumption. In short, results from this two variable VAR suggest that "consumption shocks" convey information about income many periods into the future. As Cochrane (1994b) stresses, a natural explanation for the finding that consumption innovations predict much of future output is that agents have some advance knowledge about future income that they use when making consumption decisions. This has come to be known in the literature as the "news shock" hypothesis.

Our three-variable VARs can be thought of as an extension of Cochrane's exercise. E5Y

personally experience layoffs. The typical respondent who says that the national economy will exhibit "periods of widespread unemployment or depression" is predicting that a significant minority of others will experience layoffs while his or her own income is stable by comparison.

${ }^{9}$ The key difference is that we focus on both short-run and medium to longer run links between confidence and activity. Since the short-run implications of a confidence innovation are modest, researchers that focused on the short-run found only a modest role for confidence. Also important is the difference between impulse responses, which offer point estimates of the effect of confidence innovations on forecasts, and incremental $R^{2}$ measures, which measure the extent to which forecast errors are reduced by inclusion of confidence in the information set. 
can be thought of as a signal about of expectations of future output. One might then entertain the hypothesis that E5Y is a sufficient statistic for agents' knowledge about future output. If this were the case, when E5Y is ordered first, the impulse responses of income and consumption to a consumption innovation would be modest; the news shock, which shows up in Cochrane's two-variable VAR as a consumption innovation would show up mostly in the response to the E5Y innovation. Alternatively, along the lines of the simplest versions of the permanent income hypothesis, consumption might be a sufficient statistic for "news", so that when consumption is ordered before E5Y, the latter variable is redundant. The variance decompositions in Figure 4 indicate that neither of these polar hypotheses holds; both consumption and E5Y contain information about the future that is not contained in the other measure.

Our finding that unexpected increases in confidence imply predictably higher subsequent consumption is also related to the results of Carroll, Fuhrer, and Wilcox (1994), who focus on one-period-ahead consumption growth. As noted above, this Granger causality from confidence to consumption (as well as income) growth is responsible for the shape of the impulse responses we estimate.

Carroll, Fuhrer, and Wilcox (1994) regard the Granger causality as, in part, a failure of the partial equilibrium permanent income hypothesis along the lines of short-term stickiness of consumption. Our finding that consumption tracks predictable income increases over a three year period suggests that the predictability of consumption growth is better thought of in terms of an the general equilibrium endowment economy of Lucas (1978), in which consumers believe that income will be higher in the future, but can in the aggregate do little to increase current consumption in anticipation. One implication of this interpretation is that positive confidence innovations should be associated with increases in expected real rates of return. This implication will be explored in some detail in the next sections, and we will see that, in addition to being an implication of a simple general equilibrium model, it also holds in the data.

\section{News and Animal Spirits in a DSGE Model}

It is clear that innovations to consumer confidence have interesting implications for economic activity, but it is difficult to interpret the meaning of the impulse responses without imposing more structure. In this section we develop a structural model to help understand the reducedform impulse response analysis of Section 2.

We incorporate consumer confidence into a medium scale dynamic stochastic general equilibrium (DSGE) model that is fairly standard. In addition to the "usual" frictions - price rigidity, habit formation, and adjustment costs - we also include in the model "news shocks" about future productivity growth, of which agents only observe a noisy signal. ${ }^{10}$ We interpret

\footnotetext{
${ }^{10}$ There is a growing literature studying the effects of noise, broadly defined, and economic fluctuations (Lorenzoni (2009), Angeletos and La'O (2009a and 2009b), Beaudry and Portier (2004), Blanchard, L'Hullier, and Lorenzoni (2009)).
} 
noise innovations in the signal about productivity growth as animal spirits shocks. A positive animal spirits shock means that agents are overly optimistic relative to the true state of the economy. Because the model is a fairly standard New Keynesian DSGE model, we leave a full description and derivation to the Appendix. Here we focus on how we incorporate news, animal spirits, and confidence into the model.

We assume that the log of neutral technology, $a_{t}$, follows a random walk with drift:

$$
\begin{gathered}
a_{t}=a_{t-1}+g_{t-1}+\varepsilon_{a, t} \\
g_{t}=\left(1-\rho_{a}\right) g^{*}+\rho_{a} g_{t-1}+\varepsilon_{g_{a}, t}
\end{gathered}
$$

We assume that the drift term itself follows a stationary $\operatorname{AR}(1)$ process, with unconditional mean $g^{*}$. The drift term is dated $t-1$, so that there is some predictability of technology growth. Because of this predictability, we can interpret shocks to the expected growth rate (i.e. $\left.\varepsilon_{g_{a}, t}\right)$ as "news shocks" in the sense defined by Beaudry and Portier (2004) and others. The shock $\varepsilon_{a, t}$ is the conventional surprise technology shock.

While we assume that agents can observe the level of technology period by period, we allow them to observe only a noisy signal of the growth rate. Formally:

$$
s_{t}=g_{t}+\varepsilon_{s, t}
$$

The shock $\varepsilon_{s, t}$ is assumed to be white noise. We will interpret it as the animal spirits shock. Following a positive animal spirits shock the agents in the economy will erroneously expect higher subsequent productivity growth.

We assume that agents use the Kalman filter to form forecasts of the unobserved growth rate. To illustrate the mechanisms at work, Figure 6 shows impulse responses of $a_{t}, g_{t}$, and $g_{t \mid t}$ to each of the three shocks involving technology for the parameterization: $\rho=0.8, \sigma_{\varepsilon_{a}}=1, \sigma_{\varepsilon_{g}}=0.1$, and $\sigma_{\varepsilon_{s}}=0.1$. Note that in response to a surprise technology shock, $\varepsilon_{a, t}$, the perceived growth rate increases very slightly because agents attach some weight to the possibility that trend technology growth is on the high side but was buried in noise in the past.

We assume that confidence follows a univariate first-order autoregression:

$$
E 5 Y_{t}=\left(1-\rho_{e}\right) E 5 Y^{*}+\rho_{e} E 5 Y_{t-1}+u_{t},
$$

where the innovation in confidence, $u_{t}$, is a function of the underlying structural shocks in the economy. Because agents cannot observe the individual structural shocks, $u_{t}$ is a linear combination of the perceived innovation in the level of current technology, the perceived innovation in the expected growth rate of technology, and a pure noise term:

$$
u_{t}=\zeta_{1}\left(a_{t}-a_{t-1}-g_{t-1 \mid t-1}\right)+\zeta_{2}\left(g_{t \mid t}-\rho_{a} g_{t-1 \mid t-1}\right)+\zeta_{3} \varepsilon_{c, t}
$$

The shock $\varepsilon_{c, t}$ is a white noise process normalized to have variance of unity. It can be interpreted as measurement error in the confidence data.

The remainder of the model is standard and is presented in the Appendix. We solve the model by inducing stationarity through appropriate normalizations and then log-linearizing the equations about the balanced growth path. 


\section{Estimation}

We estimate the parameters of the model by minimizing the distance between impulse responses generated from simulations of the model and those from the actual data, thereby providing a connection to our earlier reduced form impulse response analysis. This form of estimation does not necessarily require that the empirical VARs we estimate have a structural interpretation, or even that they are correctly specified. Rather, we take the empirical impulse responses as interesting statistics that a well-specified structural model should be capable of matching.

We calibrate several of the uncontroversial parameters to conventional values used in the literature. These parameter values can be found in Table 1. The unit of time is taken to be a quarter. The discount factor is set to 0.99. Capital's share of income from a constant returns to scale Cobb-Douglas production function is set to 0.36 . We assume a quarterly depreciation rate on capital of 0.03 . The steady state growth rate of technology, $g^{*}$, is set to 0.33 percent. Given the calibration of capital's share of income, this implies steady state growth in output per worker of about 2 percent, which is consistent with post-war US data. As described in more detail in the Appendix, the model assumes a government which consumes a stochastic share of output. ${ }^{11}$ We fix the steady state share of private output consumed by the government at 20 percent. We also fix the persistence and standard deviation of government spending shocks at 0.95 and 0.25 percent, respectively. These numbers were obtained by regressing the government spending share on its own lag. Given these fixed parameters of the model, 57 percent of output goes to private consumption in the steady state while 23 percent goes to private investment. These numbers are all in line with the post-war US data.

We estimate the remaining parameters of the model to match as closely as possible impulse responses to VARs estimated in the data. While this is a limited information approach, it focuses the estimation on the question at hand - why are confidence innovations prognostic of future movements in economic activity? Our estimation strategy is similar to those of Rotemberg and Woodford (1997) and Christiano, Eichenbaum, and Evans (2005).

For our estimation we focus on impulse responses from a somewhat larger system than that shown in Section 2. In addition to confidence, consumption, and output, we also include measures of inflation and the real interest rate in the reduced form VAR model. The reasons for this are twofold. First, because the New Keynesian model is about the interaction of real and nominal variables, the responses of inflation and interest rates help to identify the parameters of the model. Second, variation in real interest rates is a central part of the general equilibrium story when there are shocks to expectations about future technology. Our measure of inflation is the annualized percentage change in the CPI, while our measure of the real interest rate is the three month treasury bill rate less one quarter ahead expected inflation (both expressed at annualized rates), where the expected inflation number is taken from the Michigan Survey of

\footnotetext{
${ }^{11}$ Government spending is an inessential component of the model. Stochastic fiscal shocks are included so that the number of structural shocks is equal to the number of variables in the empirical VAR.
} 


\section{Consumers.}

The impulse responses and confidence bands are shown in Figure 7. The responses of consumption and income to a confidence innovation (ordered first) are very similar to what was shown in the case of the three variable VARs of Section 2. Positive confidence innovations are also associated with a persistent fall in inflation and a marked increase in the real interest rate.

Let $\mathbf{M}^{*}$ denote a stacked vector of these estimated impulse responses. We include the responses of all five of the variables in the above VAR to all five orthogonalized innovations in $\mathbf{M}^{*}$, using a recursive ordering corresponding with the order in which the variables are listed above. We include the responses at horizons from impact to twenty quarters. Altering the horizons for the included impulse responses makes little difference for the results. In addition to the impulse responses, we include two other moments in the vector $\mathbf{M}^{*}$ - the autocorrelation and the standard deviation of the growth rate of output per worker. Including these additional moments is important for two reasons. First, productivity growth in the data is approximately white noise. Because we assume a serially correlated drift term in the process for technology, it is important that the variance of news shocks not be too large relative to the variance of level shocks; otherwise the resulting productivity series will exhibit too much autocorrelation. Secondly, including an unconditional measure of volatility is important because in conventional impulse response analysis the size of shocks is normalized (Canova and Sala (2009)).

For a given parameter vector $\Theta$, with dimension $q \times 1$, we simulate $H$ data sets from the model, each of the same size as the dataset used to estimate our empirical VARs. ${ }^{12}$ The shocks used to generate the simulations are drawn from mean zero normal distributions. For each simulated data set, we estimate the same five variable VAR as above (again with four lags), and compute impulse responses using the same recursive ordering. We then average the impulse responses over the $H$ simulations and compare the averaged responses to the impulse responses from the actual data. Finally, we iterate on our guess of $\Theta$ to minimize the weighted distance between the model simulated and data moments.

Let $\mathbf{M}(\boldsymbol{\Theta})$ denote the $h \times 1$ vector of impulse responses and moments from the simulated data for a given parameter vector, $\boldsymbol{\Theta}$. Our estimator is the solution to the following problem:

$$
\widehat{\boldsymbol{\Theta}}=\arg \min \quad \boldsymbol{\Gamma}(\boldsymbol{\Theta})=\left(\mathbf{M}^{*}-\mathbf{M}(\boldsymbol{\Theta})\right)^{\prime} \mathbf{W}^{-1}\left(\mathbf{M}^{*}-\mathbf{M}(\boldsymbol{\Theta})\right)
$$

$\mathbf{W}$ is a diagonal matrix whose elements are equal to the variance of the empirical moments of the actual data. These variances are the sample variances from bootstrap simulations of the empirical VAR. Weighting the discrepancy between data and model responses by the inverse of the variances of the responses in the data places more weight on responses which are estimated with more precision.

Under regularity conditions, the limiting distribution of $\Theta^{*}$ is approximately: ${ }^{13}$

\footnotetext{
${ }^{12}$ In practice, each artificial data set contains $T+100$ observations, where $T$ is the number of observations in the actual data set. We discard the first 100 observations so as to limit the influence of starting values.

${ }^{13}$ See Smith (1993) or Dejong and Dave (2007).
} 


$$
T^{-\frac{1}{2}}\left(\boldsymbol{\Theta}^{*}-\boldsymbol{\Theta}\right) \rightarrow N\left(0,\left(\mathbf{D}^{\prime} \mathbf{W}^{-1} \mathbf{D}\right)^{-1}\right)
$$

The matrix $\mathbf{D}=\frac{\partial \mathbf{M}(\boldsymbol{\Theta})}{\partial \boldsymbol{\Theta}}$ is a $h \times q$ Jacobian matrix of derivatives of the moments with respect to the parameters. In practice, we calculate this matrix numerically, evaluating it at the estimated parameter vector. As our model is overidentified $(h>q)$, we can easily construct formal tests of model fit similarly to Hansen's (1982) $J$ test.

\subsection{Results}

The parameter estimates and standard errors for our benchmark estimation of the model are presented in Table 2. We use $H=2500$ simulations.

The first four parameters in Table 2 concern the confidence equation in the model: $\zeta_{1}$ is the coefficient on the innovation in perceived current technology, $\zeta_{2}$ is the coefficient on innovation in the perceived growth rate, $\zeta_{3}$ governs the importance of noise, and $\rho_{e}$ governs the persistence of confidence. Consistent with the impression conveyed by a time series plot of the data, confidence is estimated to be highly persistent but stationary $\left(\rho_{e}=0.94\right)$. The coefficient on the expected growth rate innovation is much larger than the coefficients on the innovation in current technology and noise, though this partly reflects the fact that the innovation variance of the expected growth rate is much smaller than the other two disturbances that affect confidence.

The next three parameters in the table govern the stochastic process for technology. The standard deviation of current technology shocks is much higher than the standard deviation of news shocks $(0.58$ vs. 0.17$)$. News shocks are estimated to be fairly persistent, with $\rho_{g_{a}}=0.73$. These parameters imply that a one standard deviation growth shock is expected to raise the level of technology in the long run by 0.7 percent. The estimated standard deviation of current technology shocks is in line with estimates based on Solow residual regressions.

The next three parameters in the table describe the central bank's interest rate rule. We find that interest rates are fairly persistent $\left(\rho_{i}=0.66\right)$, with the bank responding fairly aggressively to both deviations of inflation from target and deviations of output growth from trend $\left(\phi_{\pi}=1.31\right.$ and $\phi_{y}=0.94$, respectively). The estimated standard deviation of monetary policy shocks is 0.13 percent.

Our estimate of the degree of habit formation in consumption, $\kappa$, is 0.31 . This is lower than most estimates, which are in the neighborhood of 0.5 to 0.8. Nevertheless, the standard error on $\kappa$ is large and does not permit rejection of the hypothesis of values in this range. Our estimate of the elasticity of the capital adjustment cost function is $\gamma=0.16$, while our estimate of the Frisch labor supply elasticity is $\eta=1.32$. The number for the labor supply elasticity is consistent with a wide range of empirical estimates, including Kimball and Shapiro's (2003) central estimate of unity.

The elasticity of demand for intermediate goods is estimated to be about 13, implying a steady state markup of price over marginal cost of 7.5 percent, which is broadly consistent with 
the estimates in Basu and Fernald (1997). We estimate the Calvo parameter, $\theta$, governing price-stickiness, to be 0.76 . This implies an average duration between price changes of about a year, and is in the range of both micro (Bils and Klenow (2004)) and macro (Gali and Gertler (1999)) estimates. The estimated standard deviation of animal spirits shocks is 0.13.

Figure 8 shows the empirical impulse responses to a confidence innovation from the five variable VAR in the data (solid line), the 90 percent bootstrap confidence region from the data (shaded gray area), and the average responses to a confidence innovation from the simulations of the model at the estimated parameters (dashed line). The dotted lines give the 90 percent confidence region from the simulations. Overall, the model does a good job of replicating the responses in the data. The averaged simulated responses from the estimated model lie within the confidence bands of the responses in the data at most horizons. Further, the implied dynamics in the model are similar - qualitatively, and, for the most part, quantitatively. ${ }^{14}$ The responses of the variables of the model to the other orthogonalized VAR innovations closely replicate their empirical counterparts, but are omitted for space considerations. The mean autocorrelation of productivity growth across the simulations comes out to be 0.05 (as opposed to 0.03 in the data), while the volatility of productivity growth is 0.71 percent (as opposed to 0.67 in the data).

Figure 9 shows the responses of selected variables to both news and animal spirits in the theoretical model at the estimated parameter values. The impact effect of a favorable news shock on output is approximately zero, though the point estimate is negative. ${ }^{15}$ Thereafter output smoothly approaches its new steady state value. Note that this output movement occurs because output tracks movements in true technology, not because news shocks induce large business cycle deviations from trend. In response to good news, inflation falls on impact in response and is estimated to be fairly persistently below its steady state. Real interest rates rise, which is consistent with the expected growth in consumption following such a shock. Confidence is persistently high following a good news shock.

The most notable feature of the theoretical impulse responses to an animal spirits shock is the negligible movement in output. The response of output to a positive animal spirits shock is slightly negative on impact (as is the response to a news shock) before becoming slightly positive and reverting. Inflation falls in response to an animal spirits shock, while real interest rates and consumer confidence rise. The magnitudes of the inflation and real rate responses are not negligible, though not overwhelming either. None of these responses to animal spirits are very persistent. In the model at the estimated parameter values, agents quickly learn about the reliability of signals regarding the growth rate. The final graph in Figure 9 shows the response

\footnotetext{
${ }^{14} \mathrm{~A}$ partial exception is the case of the real interest rate, which rises more markedly in the data than in the model simulation.

${ }^{15}$ Though not shown, consumption rises and investment falls on impact. The negative impact effect of a news shock and the negative co-movement between consumption and investment are consistent with the responses estimated in Barsky and Sims (2010).
} 
of confidence to a pure noise shock (which, by construction, has no effect on any of the other variables in the model).

Table 3 presents the variance decomposition of confidence, consumption, and output at various horizons in the model at the estimated parameter values. News shocks explain roughly one half of the innovation variance in measured confidence. Animal spirits shocks explain 25 percent of the confidence innovation variance, pure noise (measurement error) accounts for 22 percent, and the innovation in the current level of technology accounts for a mere 1 percent. News shocks have only a small quantitative impact on either consumption or output at high frequencies, but account for a growing share of the forecast error variance of these variables at longer horizons. Though news shocks do not induce business-cycle like co-movement at very high frequencies, they account for over half of the forecast variance of output and consumption at long horizons. Animal spirits shocks account for negligible shares of the forecast error variances of consumption and output at all frequencies. ${ }^{16}$

Although it is not possible to recover exactly the underlying deep shocks from structural estimation, it is possible to form retrospective estimates of the underlying states and shocks using the Kalman smoother. Given retrospective estimates of the states, we can recover estimates of the underlying shocks, which allows us to compute historical simulations. Figure 10 plots historical decompositions of consumer confidence, indicating the role of each of the four shocks leading to movements in confidence in the model. In panel (a) we see that news shocks account for most of the middle to low frequency movements in confidence. In particular, bad news shocks account for the simultaneous productivity growth slowdown and low confidence of the 1970s and good news shocks for the reverse situation in the 1990s. As shown in panel (b), animal spirits shocks are not responsible for sustained movements in confidence despite their nonnegligible contribution to the confidence innovation. Technology shocks account for essentially no movements in measured confidence, while measurement error accounts for a fair degree of the movements in confidence over time (panels (c) and (d)).

It is clear that news shocks are an important source of variation in confidence. The variance decompositions indicate that animal spirits have a significant effect on confidence innovations, but negligible effects on consumption and income. Thus the relationship between confidence and the activity variables is almost entirely driven by news shocks. Confidence innovations are noisy signals about medium term economic growth, but the noise itself has few interesting economic consequences.

According to our model, growth in technology is exogenous. The news driven relationship between confidence innovations and subsequent economic activity is not causal; it simply reflects the fact that news shocks provide advance knowledge of productivity developments that would occur irrespective of consumer beliefs. One might wonder how the interpretation would change if

\footnotetext{
${ }^{16}$ Preference, government spending, and monetary policy shocks account for the remaining forecast variance of output and consumption.
} 
technology were endogenous. If animal spirits or other demand shocks cause short run increases in activity, these might ultimately lead to a rise in TFP through learning-by-doing or some similar endogenous growth mechanism. Thus we might mistakenly be concluding that news shocks are the driving force rather than the demand shocks which are sparking the endogenous growth. But the fact is that there are not substantial short run increases in economic activity following a confidence innovation, and the prerequisite for endogenous growth is not met. It appears that foreseeable shifts in exogenous technical progress are the most natural way to explain the delayed "reaction" of activity to confidence innovations.

Our result that confidence innovations are highly correlated with innovations to trend productivity growth is perhaps surprising to observers who place little faith in the survey responses of ordinary households. As such, we close the empirical section of the paper with a bit of non-structural corroborating evidence. Figure 11 plots the HP trend growth rate of labor productivity (the BLS measure of output per hour in the non-farm business sector) along with E5Y. The positive co-movement between these series is strong, and is consistent with our structural econometric analysis.

\subsection{Discussion}

At the estimated parameter values of our model, animal spirits shocks have very little effect on the real variables of the model - with the exception of the real interest rate. It turns out that it is difficult for an innovation to a signal about some underlying fundamental (whether or not the signal is ultimately valid) to have much of an effect on economic activity for any realistic parameter values. On the "supply side", the reason is that, in the absence of any change in current marginal productivity, it is difficult to get the substantial increase in labor input needed to produce significantly increased output. ${ }^{17}$ This is by now a well-understood difficulty of generating business cycles from news about future technology. The same difficulty holds for animal spirits shocks, which in our model are simply false news shocks. In this sense the fact that animal spirits effects have a hard time generating business cycle-like movements in output is not surprising.

To understand what happens on the "demand side", consider the general equilibrium of a pure endowment economy along the lines of Lucas (1978). Even though households would like, for a given interest rate, to increase their consumption immediately in response to a good signal, the interest rate must adjust so that consumption is equal to the endowment each period. In this framework, neither news nor animal spirits shocks can have any effect at all on output and consumption.

Of course, this extreme scenario does not characterize our model, which features capital and endogenous labor effort. However, the same general equilibrium mechanism is at work. As

\footnotetext{
${ }^{17}$ Indeed, for our estimated parameter, there is a slight decrease in labor supply on impact. A drop in labor input in response to news shocks is a common result in DSGE models.
} 
shown in Figure 9, in the estimated model real interest rates rise on impact in response to positive news about future productivity growth. This occurs regardless of whether the signal is genuine news or an animal spirits shock. The increase in the real rate works to suppress the increase in demand and leaves quantity variables largely unchanged in response to a positive signal. Only after the level of technology begins to change following a true news shock do quantity variables move substantially.

It appears that for animal spirits to have important economic consequences, the general equilibrium forces working against them must be weak. To verify this conjecture, we conduct an experiment in which we pick the parameters of the model not to match any features of the data but rather to maximize the real effects of animal spirits shocks. The resulting responses of output and other key endogenous variables under this parameter configuration are shown in Figure 12. It is clear that there do exist parameterizations of the model in which animal spirits can "matter". 18

The parameter configuration leading to large real effects of animal spirits is precisely one which mitigates general equilibrium mechanisms. In particular, the "optimal" parameter vector includes $\theta=0.999$ and $\phi_{y}=0$. In other words, prices are almost perfectly rigid and the central bank does not adjust interest rates to output fluctuations. From the interest rate rule, the virtual absence of movements in inflation combined with the absence of interest rate responses to output, real interest rates effectively become fixed. In this case, consumption must jump to its expected steady state level in response to signals observed by consumers (the "random walk" property of the partial equilibrium version of the permanent income hypothesis). This parameter configuration is essentially identical to the one emphasized in Blanchard, L'Hullier, and Lorenzoni (2009).

In addition to being at odds with the microeconomic evidence on price adjustment (Bils and Klenow (2004)), these parameters also lead to counterfactual implications for the model responses to a confidence innovation. As an interesting exercise, we fix $\theta=0.999$ and $\phi_{y}=0$, and repeat our estimation exercise from above. In other words, fixing these two parameters, we estimate the remaining parameters to best match the empirical impulse responses from our five variable VAR. The impulse responses to a confidence innovation for the best-fitting combination of parameters are shown in Figure 13. It is immediately obvious that the fit is much worse. The responses of both output and consumption to a confidence innovation are largest on impact as opposed to at longer horizons, and neither inflation nor the real interest rate move at any horizon. The formal likelihood ratio statistic is over 200, easily rejecting this restricted version of the model in favor of the unrestricted version estimated above. At parameter configurations not very far from this extreme (e.g. a Calvo parameter of $\theta=0.9$ instead of near unity), animal

\footnotetext{
${ }^{18}$ Even so, while the magnitude of the impact response of output under this parameter configuration is large, the response is not very persistent. This is a generic issue with these models - under Kalman learning, agents soon realize their mistakes and the effects of erroneous optimism/pessimism quickly vanish.
} 
spirits simply cease to have large effects. It appears necessary to almost literally "turn off" general equilibrium to give animal spirits much chance of mattering.

We began this project focusing on the long run implications of confidence for economic activity. We initially took this lack of reversion in the responses to be evidence against an important animal spirits component. The theoretical result of Blanchard, L'Hullier, and Lorenzoni (2009) that in the signal extraction framework there can be no ex ante reversion to any structural shock, forced us to reconsider this argument. It remains true that the presence of a powerful long-run response of output to confidence is evidence for an news component of confidence. If it were not the case that confidence innovations are often indicative of true permanent technology movements there would be no reason for such behavior. However, as Blanchard, L'Hullier, and Lorenzoni (2009) correctly assert, in the signal extraction model the absence of mean reversion in the response of consumption to the composite signal measured by confidence does not prove that there is not also an important animal spirits effect. It is now clear that the principal feature of the data that refutes the importance of animal spirits is not the absence of long-run reversion but the near zero responses of consumption and output to a confidence innovation at short horizons. The fact that the empirical responses of quantity variables at high frequencies are small suggests animal spirits are relatively unimportant.

One limitation of the approach in this paper is that our model of confidence concerns beliefs about an exogenous fundamental variable (namely productivity growth). We do not cover the case in which the confidence concerns not an agent's own beliefs about fundamentals but higher order beliefs as in Angeletos and Lao, (2009a) and (especially) (2009b). In such models, a belief that other agents have optimistic forecasts of economic activity is potentially expansionary. Such models seem to us to have significant potential, but are not currently in a dynamic form that can be used directly for estimation of a structural model. At the same time, we suspect that the same general equilibrium forces that limit animal spirits effects in our model would also put a damper on animal spirits effects in this alternative environment.

\section{$5 \quad$ What is the News?}

In the VARs estimated in this paper, E5Y and other overall confidence measures are roughly exogenous. With E5Y ordered first, more than 95 percent of the forecast error variance of confidence is explained by its own innovation at every horizon. Even when confidence is allowed to respond contemporaneously to innovations in other macroeconomic variables, the fraction of the forecast error variance of confidence attributable to its own innovation always exceeds 85 percent.

What kinds of news might explain these surprise movements in consumer confidence? In addition to the questions discussed in Section 2, the Michigan Survey also asks respondents to report any recent "news heard" concerning the economy. In light of our results of the previ-

ous section pointed towards the "information" or news view of confidence, it seems natural to 
conclude with a brief investigation of the relationship between this reported economic news and responses to the survey questions concerning overall expectations of aggregate and individual economic conditions.

Survey respondents give answers to a question asking them to report favorable or unfavorable economic news, and their answers are tabulated into arbitrary, but generally well-defined, categories. ${ }^{19}$ Figure 14 presents spike plots for several of the more popular response categories across time. Many categories record very few responses in a typical quarter. The most consistently popular concern news about prices and news about employment. Other responses stand out in particular time periods. Examples are a high incidence of mention of "energy crisis" during periods of the 1970s and early 1990s as well as news heard concerning the stock market sporadically across the sample period, but most frequently during the $1990 \mathrm{~s}^{20}$

In Table 4 we present coefficient estimates from regressions of the E5Y innovations from the VARs of Section 2 on selected categories of news. Most of the news heard categories have coefficients of the expected signs - favorable news is positively correlated with the confidence innovation and vice versa. Favorable or unfavorable news about general prices and favorable news about the stock market are significant covariates with the E5Y innovation at the 10 percent level or better. News about employment and favorable news about the stock market are insignificantly correlated with the E5Y innovation. Unfavorable news about government policies also has a statistically significant coefficient at the 10 percent level. The adjusted $R^{2}$ from these regressions ranges from 0.10 to 0.15 , suggesting that the bulk of E5Y innovations remain inexplicable from particular categories of news heard. Use of other more obscure categories of news heard produce insignificant coefficient estimates that frequently reduce the adjusted $R^{2}$ in the regressions. We also ran a specifications that included the news heard variables in the VARs directly. This produced impulse responses of consumption and income which were much weaker than when using the broader confidence measures.

Innovations to measures of consumer confidence evidently convey information about income many periods into the future, much of which is not reflected in current consumption or income innovations, and the surprise movements in the confidence measures are not attributable to tangible news. Some might find it surprising that the answers of largely naïve respondents to rather crude questions could be so informative. As emphasized in Cochrane (1994b), however, such expressions of surprise fail to recognize the role of information aggregation. As Cochrane puts it (see p. 350), "Ask a consumer about next year's GDP, and he will say 'I don't know.' But he may know that his factory is closing, and hence he is consuming less. This idiosyncratic shock

\footnotetext{
${ }^{19}$ The specific questions are: "During the last few months, have your heard of any favorable or unfavorable changes in business conditions?" If the answer is yes, the follow up question is: "What did you hear?"

${ }^{20}$ The data summarizing responses to the "news heard" questions do not have the statistical properties of "news" in the rational expectations sense. Rather, the data on news reports are highly serially correlated. This may be due to gradual diffusion of news reports along the lines of Carroll's (2003) epidemiological model, or it may reflect merely the wording of the question, which refers to news heard in the "last several months".
} 
is correlated with future GDP." Just as consumption data aggregate idiosyncratic information, consumer confidence data aggregate information from many sources and many individuals.

\section{Conclusion}

This paper has sought to provide an answer to an unresolved question in economics: what is the economic meaning and significance of consumer confidence? We began by showing that surprise movements in confidence are prognostic of long-lasting movements in macroeconomic variables. While on its face this seems to be prima facie evidence that consumer confidence conveys information about economic fundamentals, econometric issues that arise in the context of signal extraction problems limit the conclusions that can be drawn from the reduced form relationships in the data. We therefore proceeded to develop and estimate a DSGE model encompassing both the animal spirits and information views of confidence. Our empirical results suggest that fundamental news is the main driving force behind the observed relationship between confidence and subsequent economic activity. Animal spirits shocks have only limited effects. Our analysis sheds light on the general equilibrium mechanisms that make it difficult for non-fundamental noise to generate large economic fluctuations. 


\section{References}

[1] Angeletos, George-Marios and Jennifer La'o. "Income Information, Higher Order Beliefs, and Price Inertia." Journal of Monetary Economics. October 2009, 19-37.

[2] Angeletos, George-Marios and Jennifer La'o. "Noisy Business Cycles." NBER Macroeconomics Annual 2009.

[3] Barsky, Robert B. and Eric R. Sims. "News Shocks and Business Cycles." Working paper, University of Notre Dame, 2010.

[4] Beaudry, Paul and Franck Portier. "An Exploration into Pigou's Theory of Cycles." Journal of Monetary Economics, September 2004, 1183-1216.

[5] Bils, Mark and Peter Klenow. "Some Evidence on the Importance of Sticky Prices." Journal of Political Economy, October 2004, 947-985.

[6] Blanchard, Olivier. "Consumption and the Recession of 1990-1991." American Economic Review, May 1993, 270-274.

[7] Blanchard, Olivier, Jean-Paul L'Hullier, and Guido Lorenzoni. "News, Noise, and Fluctuations: An Empirical Exploration." NBER WP 15015, 2009.

[8] Calvo, Guillermo. "Staggered Prices in a Utility Maximizing Framework." Journal of Monetary Economics, September 1983, 383-398.

[9] Canova, Fabio and Luca Sala. "Back to Square One: Identification Issues in DSGE Models." Journal of Monetary Economics, May 2009, 431-449.

[10] Carroll, Christopher D. "Macroeconomic Expectations of Households and Professional Forecasters." Quarterly Journal of Economics, February 2003, 269-298.

[11] Carroll, Christopher D., Jeffrey C. Fuhrer and David W. Wilcox. "Does Consumer Sentiment Forecast Household Spending? If so, Why?" American Economic Review, December 1994, 1397-1408.

[12] Christiano, Lawrence J., Martin Eichenbaum, and Charles L. Evans. "Nominal Rigidities and the Dynamic Effects of a Shock to Monetary Policy." Journal of Political Economy, February 2005, 1-45.

[13] Clarida, Richard, Jordi Gali and Mark Gertler. "Monetary Policy and Macroeconomic Stability: Evidence and Some Theory." Quarterly Journal of Economics, 115, 2000, 147180. 
[14] Cochrane, John H. "Permanent and Transitory Components of GNP and Stock Prices." Quarterly Journal of Economics, February 1994a, 241-266.

[15] Cochrane, John H. "Shocks." Carnegie-Rochester Conference Series on Public Policy, December 1994b, 295-364.

[16] Dejong, David and Chetan Dave. Structural Macroeconometrics. Princeton: Princeton University Press, 2007.

[17] Dominitz, Jeff and Charles Manksi. "How Should We Measure Consumer Confidence?" Journal of Economic Perspectives, Spring 2004, 51-66.

[18] Farmer, Roger. The Macroeconomics of Self-Fulfilling Prophecies. Cambridge, MA: MIT Press. 1999.

[19] Gali, Jordi and Mark Gertler. "Inflation Dynamics: A Structural Econometric Analysis." Journal of Monetary Economics, October 1999, 195-222.

[20] Gertler, Mark. Course Notes for Graduate Macro I. New York University, 2000.

[21] Hall, Robert E. "Macro Theory and the Recession of 1990-1991." American Economic Review, May 1993, 275-279.

[22] Hall, Robert E. "Stochastic Implications of the Life Cycle Permanent Income Hypothesis: Theory and Evidence." Journal of Political Economy, December 1978, 971-987.

[23] Hansen, Lars. "Large Sample Properties of Generalized Method of Moments Estimators." Econometrica, July 1982, 1269-1286.

[24] Kilian, Lutz. "Small Sample Confidence Intervals for Impulse Response Functions." Review of Economics and Statistics, May 1998, 218-230.

[25] Kimball, Miles S. and Matthew D. Shapiro. "Labor Supply: Are the Income and Substitution Effects Both Large or Both Small?" University of Michigan Working Paper, May 2003.

[26] Lorenzoni, Guido. "A Theory of Demand Shocks." American Economic Review, December 2009, 2050-2084.

[27] Lucas, Robert E. "Asset Prices in an Exchange Economy." Econometrica, November 1978, 1429-1445.

[28] Pesaran, H. Hashem and Yongcheol Shin. "Generalized Impulse Response Analysis in Linear Multivariate Models." Economics Letters, January 1998, 17-29. 
[29] Rotemberg, Julio and Michael Woodford. "An Optimization Based Econometric Framework for the Evaluation of Monetary Policy." NBER Macroeconomics Annual 1997, 297344.

[30] Smith, Anthony. "Estimating Nonlinear Time Series Models Using Simulated Vector Autoregressions." Journal of Applied Econometrics, December 1993, S63-84.

[31] Woodford, Michael. Interest and Prices: Foundations of a Theory of Monetary Policy. Princeton, NJ: Princeton University Press, 2003. 


\section{Appendix 1: Confidence Data}

\section{Questions:}

E5Y: Looking ahead, which would you say is more likely - that in the country as a whole we'll have continuous good times during the next five years, or that we'll have periods of widespread unemployment or depression, or what?

E12M: Now turning to business conditions in the country as a whole - do you think that during the next twelve months we'll have good times financially or bad times or what?

PFE: Now looking ahead - do you think that a year from now you (and your family living there) will be better off financially, worse off, or just about the same as now?

News Heard: During the last few months, have your heard of any favorable or unfavorable changes in business conditions?

For most questions (including E5Y, E12M, and PFE), individuals are given three answer choices that amount to "favorable", "neutral" or "don't know", and "unfavorable". The "relative score" - the variable we use in this paper - is then constructed as the percentage giving a favorable response less the percentage giving an unfavorable response plus one hundred. Thus, a relative score of 100 indicates that an equal number of people gave a favorable response as an unfavorable response. If 30 percent of respondents give a favorable response and 20 percent given an unfavorable response, with the remaining 50 percent either "neutral" or "don't know", then the relative score will be 110 (i.e. $30-20+100$ ). If, out of 100 people, 1 person switches from an unfavorable response to a neutral response, the index score will go up by 1 . If that person switches from unfavorable to favorable, the index score goes up by 2 . If someone leaves the state of "neutral" to either "favorable" or "unfavorable" the index score moves up or down by 1 .

The Index of Consumer Expectations (ICE) is constructed based on the relative scores for PFE, E12M, and E5Y as follows:

$$
I C E=\frac{P F E+E 12 M+E 5 Y}{4.1134}+2.0
$$

The Index of Consumer Sentiment (ICS) is constructed based on the relative scores for the PFE, E12M, and E5Y, plus two other questions. The first we'll call PFP and is similar to PFE, except that it asks respondents to make a comparison of their current financial situation

relative to one year ago. The second we'll call DUR and it asks respondents whether or not it is currently a good time to buy "large household items" (i.e. durable goods). The ICS is constructed as:

$$
I C S=\frac{P F E+E 12 M+E 5 Y+D U R+P F P}{6.7558}+2.0
$$




\section{Appendix 2: Model}

The model of Section 3 is a relatively standard DSGE model. It is comprised of households, who consume final goods and supply labor; final goods firms, who convert intermediate goods into a final good; intermediate goods firms, who are monopolistically competitive and face time dependent nominal-price stickiness; capital goods producers, who produce capital using final goods output, and who also face convex adjustment costs. The description here closely follows the presentation in a set of notes prepared by Gertler (2000).

\section{Households:}

Household choose consumption, labor supply, and real holdings of riskless one period bonds to maximize lifetime utility:

$$
\begin{gathered}
\max _{C_{t}, N_{t} B_{t}} \sum_{i=0}^{\infty} \beta^{t} E_{0}\left(\ln \left(C_{t}-\kappa C_{t-1}\right)-\frac{N_{t}^{1+1 / \eta}}{1+1 / \eta}\right) \\
\text { s.t. } \\
C_{t}+B_{t}=w_{t} N_{t}-T_{t}+\left(1+r_{t-1}\right) B_{t-1}+\Pi_{t}
\end{gathered}
$$

$\beta$ is a discount factor, $\kappa$ indexes the degree of habit persistence in consumption, and $\eta$ is the Frisch labor supply elasticity. $w_{t}$ is the real wage, $r_{t}$ is the real interest rate, $T_{t}$ is lump sum taxes/transfers, and $\Pi_{t}$ denotes profits. The solution to the problem is the familiar Euler equation and intratemporal labor supply condition:

$$
\begin{aligned}
\Lambda_{t} & =\frac{1}{C_{t}-\kappa C_{t-1}}-E_{t} \frac{\beta \kappa}{C_{t+1}-\kappa C_{t}} \\
\Lambda_{t} & =\beta\left(1+r_{t}\right) \Lambda_{t+1} \\
N_{t}^{1 / \eta} & =\Lambda_{t} w_{t}
\end{aligned}
$$

\section{Final Goods:}

The final good is a CES aggregate of a continuum of intermediate goods, indexed by $j$ :

$$
Y_{t}=\left[\int_{0}^{1} Y_{t}(j)^{\frac{\xi-1}{\xi}} d j\right]^{\frac{\xi}{\xi-1}}
$$

Final goods producers are competitive and take the price of intermediate goods as given. Cost minimization yields the demand function for intermediate goods:

The price index is $P_{t}=\left[\int_{0}^{1} P_{t}(j)^{1-\xi}\right]^{\frac{1}{1-\xi}}$.

$$
Y_{t}(j)=\left[\frac{P_{t}(j)}{P_{t}}\right]^{-\xi} Y_{t}
$$

\section{Intermediate Goods:}


Intermediate goods firms, indexed by $j$ along the unit interval, face the above demand curve for their product. They have the following constant returns to scale production functions:

$$
Y_{t}(j)=A_{t} K_{t}(j)^{\alpha} N_{t}(j)^{1-\alpha}
$$

Capital is freely mobile across firms, but is predetermined for the economy as a whole. Costminimization yields labor and capital demand curves:

$$
\begin{aligned}
& w_{t} / p_{t}(j)=M C_{t}(j)(1-\alpha) A_{t} K_{t}(j)^{\alpha} N_{t}(j)^{-\alpha} \\
& R_{t} / p_{t}(j)=M C_{t}(j) \alpha A_{t} K_{t}(j)^{\alpha-1} N_{t}(j)^{1-\alpha}
\end{aligned}
$$

$R_{t}$ is the real rental price of capital and $w_{t}$ is the real wage. $M C$ is marginal cost.

Intermediate goods firms are not freely able to adjust their prices period by period. They face a constant probability, $1-\theta$, of being able to adjust their price in any period. A firm able to adjust its price at time $t$ sets its price to maximize:

$$
\max _{P_{t}(j)} \quad \sum_{i=0}^{\infty}(\theta \beta)^{i} E_{t}\left(\frac{\Lambda_{t+i}}{\Lambda_{t}} \frac{1}{P_{t+i}}\left(P_{t}(j) Y_{t+i}(j)-T C_{t+i}\left(Y_{t+i}(j)\right)\right)\right.
$$

$\beta^{i} \frac{\Lambda_{t+i}}{\Lambda_{t}}$ is the stochastic discount factor, and the problem is maximized subject to the demand function for the intermediate good given above. The solution is an optimal reset price which will be common across all firms updating in any period:

$$
P_{t}^{*}=(1+\mu) \frac{E_{t}\left(\sum_{i=0}^{\infty}(\theta \beta)^{i} \frac{\Lambda_{t+i}}{\Lambda_{t}} M C_{t+i} Y_{t+i}(j)\right)}{E_{t}\left(\sum_{i=0}^{\infty}(\theta \beta)^{i} \frac{\Lambda_{t+i}}{\Lambda_{t}} Y_{t+i}(j)\right)}
$$

$1+\mu=\frac{\xi}{\xi-1}$ is the steady state gross markup. In the absence of price rigidity $(\theta=0)$, all firms would set price equal to a constant markup over marginal cost each period.

\section{Capital Producers:}

There are a continuum of capital producers along the unit interval, index by $v$. The production function for new capital is:

$\phi$ is an increasing and concave function. The firm solves:

$$
Y_{t}^{k}(v)=\phi\left(\frac{I_{t}(v)}{K_{t}(v)}\right) K_{t}(v)
$$

$$
\max _{I_{t}(v), K_{t}(v)} Q_{t} Y_{t}^{k}(v)-I_{t}(v)-R_{t}^{K} K_{t}(v)
$$

$Q_{t}$ is the price of installed capital and $R_{t}^{K}$ is the rental rate for producing new capital. The first order conditions are:

$$
\begin{aligned}
Q_{t} \phi^{\prime}(\cdot) & =1 \\
Q_{t}\left(\phi\left(\frac{I_{t}(v)}{K_{t}(v)}\right)-\frac{I_{t}(v)}{K_{t}(v)} \phi^{\prime}\left(\frac{I_{t}(v)}{K_{t}(v)}\right)\right) & =R_{t}^{k}
\end{aligned}
$$

The parameter $\gamma$ denotes the elasticity of the adjustment cost function.

\section{Aggregation, Policy, and Resource Constraints}


One can show that the aggregate production function takes the same form as the production function for intermediate goods producers in the region of the steady state:

$$
Y_{t}=A_{t} K_{t-1}^{\alpha} N_{t}^{1-\alpha}
$$

The time subscript on the aggregate capital stock reflects that newly produced capital is not available for one period, even though capital can move freely between intermediate goods firms within period. The aggregate capital stock accumulates according to:

The aggregate resource constraint is:

$$
K_{t}=\phi\left(\frac{I_{t}}{K_{t}}\right) K_{t}+(1-\delta) K_{t-1}
$$

$$
Y_{t}=C_{t}+I_{t}+G_{t}
$$

We assume that the government consumes a stochastic share of output. We assume that the government share of output follows a stationary $\operatorname{AR}(1)$ in the log:

$$
\ln \left(\frac{G}{Y}\right)_{t}=\left(1-\rho_{g}\right) \ln \left(\frac{G}{Y}\right)+\rho_{g} \ln \left(\frac{G}{Y}\right)_{t-1}+\varepsilon_{G, t}
$$

The government finances its (exogenous) purchases with lump sum taxes on households, $T_{t}$. The government sets monetary policy according to a Taylor type (1993) rule of the form:

$$
i_{t}=\rho_{i} i_{t-1}+\left(1-\rho_{i}\right) \phi_{\pi}\left(\pi_{t}-\pi^{*}\right)+\left(1-\rho_{i}\right) \phi_{y}\left(\Delta Y_{t}-\Delta Y^{*}\right)+\varepsilon_{i, t}
$$

$\Delta Y_{t}$ is output growth. We restrict the parameters of this rule to be leave the economy in the region of determinacy (see Woodford (2003)). 
Table 1: Calibrated Parameter Values

\begin{tabular}{|l|l|}
\hline Parameter & Value \\
\hline$\beta$ & 0.99 \\
\hline$\alpha$ & 0.36 \\
\hline$\delta$ & 0.03 \\
\hline$g^{*}$ & 0.0033 \\
\hline$\left(\frac{G}{Y}\right)^{*}$ & 0.20 \\
\hline$\rho_{G}$ & 0.95 \\
\hline$\sigma_{G}$ & 0.0025 \\
\hline
\end{tabular}

Note: these are the parameters of the model of Section 3 and the Appendix that are calibrated.

Table 2: Benchmark Parameter Estimates

\begin{tabular}{|l|l|l||l||l|l|}
\hline \hline Parameter & $\zeta_{1}$ & $\zeta_{2}$ & $\zeta_{3}$ & $\rho_{e}$ & $\rho_{g_{a}}$ \\
\hline \hline $\begin{array}{l}\text { Estimate } \\
\text { S.E. }\end{array}$ & $\begin{array}{l}(0.01 \\
(0.63)\end{array}$ & $\begin{array}{l}32.76 \\
(2.03)\end{array}$ & $\begin{array}{l}3.78 \\
(0.81)\end{array}$ & $\begin{array}{l}0.94 \\
(0.01)\end{array}$ & $\begin{array}{l}0.73 \\
(0.08)\end{array}$ \\
\hline \hline Parameter & $\sigma_{\varepsilon_{g_{a}}}$ & $\sigma_{\varepsilon_{a}}$ & $\phi_{\pi}$ & $\phi_{y}$ & $\rho_{i}$ \\
\hline \hline $\begin{array}{l}\text { Estimate } \\
\text { S.E. }\end{array}$ & $\begin{array}{l}0.17 \\
(0.06)\end{array}$ & $\begin{array}{l}0.58 \\
(0.12)\end{array}$ & $\begin{array}{l}1.31 \\
(0.18)\end{array}$ & $\begin{array}{l}0.94 \\
(0.12)\end{array}$ & $\begin{array}{l}0.66 \\
(0.16)\end{array}$ \\
\hline \hline Parameter & $\kappa$ & $\gamma$ & $\eta$ & $\sigma_{\varepsilon_{i}}$ & $\xi$ \\
\hline \hline Estimate & 0.31 & 0.16 & 1.32 & 0.21 & 13.71 \\
S.E. & $(0.31)$ & $(0.08)$ & $(0.86)$ & $(0.11)$ & $(6.03)$ \\
\hline \hline Parameter & $\theta$ & $\sigma_{\varepsilon_{s}}$ & & & \\
\hline \hline Estimate & 0.76 & 0.13 & & & \\
S.E. & $(0.07)$ & $(0.08)$ & & & \\
\hline \hline
\end{tabular}

Note: this table shows parameter estimates from the model of Section 3. Standard errors are in parentheses. 
Table 3: Model Variance Decomposition

\begin{tabular}{|l|l|l|l|l|l|}
\hline & $h=1$ & $h=4$ & $h=8$ & $h=16$ & $h=20$ \\
\hline \hline News & & & & & \\
\hline \hline$E 5 Y$ & 0.52 & 0.71 & 0.75 & 0.77 & 0.77 \\
\hline$C$ & 0.11 & 0.25 & 0.36 & 0.47 & 0.49 \\
\hline$Y$ & 0.02 & 0.11 & 0.31 & 0.46 & 0.49 \\
\hline Animal spirits & & & & & \\
\hline \hline$E 5 Y$ & 0.25 & 0.09 & 0.06 & 0.05 & 0.04 \\
\hline$C$ & 0.06 & 0.01 & 0.00 & 0.00 & 0.00 \\
\hline$Y$ & 0.01 & 0.01 & 0.00 & 0.00 & 0.00 \\
\hline Technology & & & & & \\
\hline \hline E5Y & 0.01 & 0.01 & 0.00 & 0.00 & 0.00 \\
\hline$C$ & 0.43 & 0.48 & 0.50 & 0.48 & 0.47 \\
\hline$Y$ & 0.13 & 0.54 & 0.57 & 0.50 & 0.48 \\
\hline Noise & & & & & \\
\hline \hline E5Y & 0.22 & 0.19 & 0.19 & 0.18 & 0.18 \\
\hline
\end{tabular}

Note: this table shows the fraction of the forecast error variance of the respective variables explained by the structural shocks at different horizons in the model of Section 3 at the parameter values in Table 2 . 


\section{Table 4}

Regressions of Confidence Innovations on News Heard Categories

\begin{tabular}{|c|c|c|c|}
\hline News Heard Category & Coefficient & & \\
\hline \multirow[t]{2}{*}{ Favorable Employment } & $0.248^{* *}$ & 0.113 & 0.140 \\
\hline & $(0.13)$ & $(0.13)$ & $(0.13)$ \\
\hline \multirow[t]{2}{*}{ Favorable Prices } & $1.001^{* *}$ & $0.889^{*}$ & $1.005^{*}$ \\
\hline & $(0.51)$ & $(0.51)$ & $(0.58)$ \\
\hline \multirow[t]{2}{*}{ Unfavorable Employment } & -0.064 & -0.071 & 0.035 \\
\hline & $(0.05)$ & $(0.05)$ & $(0.06)$ \\
\hline \multirow{2}{*}{ Unfavorable Prices } & $-0.363^{* * *}$ & $-0.342^{* * *}$ & $-0.312^{* * *}$ \\
\hline & $(0.13)$ & $(0.13)$ & $(0.15)$ \\
\hline \multirow[t]{2}{*}{ Favorable Stocks } & & $0.915^{* *}$ & $0.845^{* *}$ \\
\hline & & $(0.38)$ & $(0.38)$ \\
\hline \multirow[t]{2}{*}{ Unfavorable Stocks } & & -0.235 & -0.259 \\
\hline & & $(0.16)$ & $(0.17)$ \\
\hline \multirow[t]{2}{*}{ Favorable Government } & & & 0.342 \\
\hline & & & $(0.53)$ \\
\hline \multirow[t]{2}{*}{ Unfavorable Government } & & & $-0.604^{* *}$ \\
\hline & & & $(0.24)$ \\
\hline \multirow[t]{2}{*}{ Favorable Credit } & & & -0.342 \\
\hline & & & $(0.27)$ \\
\hline \multirow[t]{2}{*}{ Unfavorable Credit } & & & 0.124 \\
\hline & & & $(0.19)$ \\
\hline \multirow[t]{2}{*}{ Energy Crisis } & & & $-0.393^{*}$ \\
\hline & & & $(0.22)$ \\
\hline Adjusted $R^{2}$ & 0.10 & 0.12 & 0.15 \\
\hline
\end{tabular}

Note: The above are coefficient estimates from a regression of the reduced form innovation in E5Y obtained from the three variable system described in Section 5 on the percentage of respondents reporting having heard either favorable or unfavorable news concerning employment, prices, or stock prices. The sample period is 1961:1 - 2007:3. OLS standard errors are in parentheses. 
Figure 1: E5Y and E12M

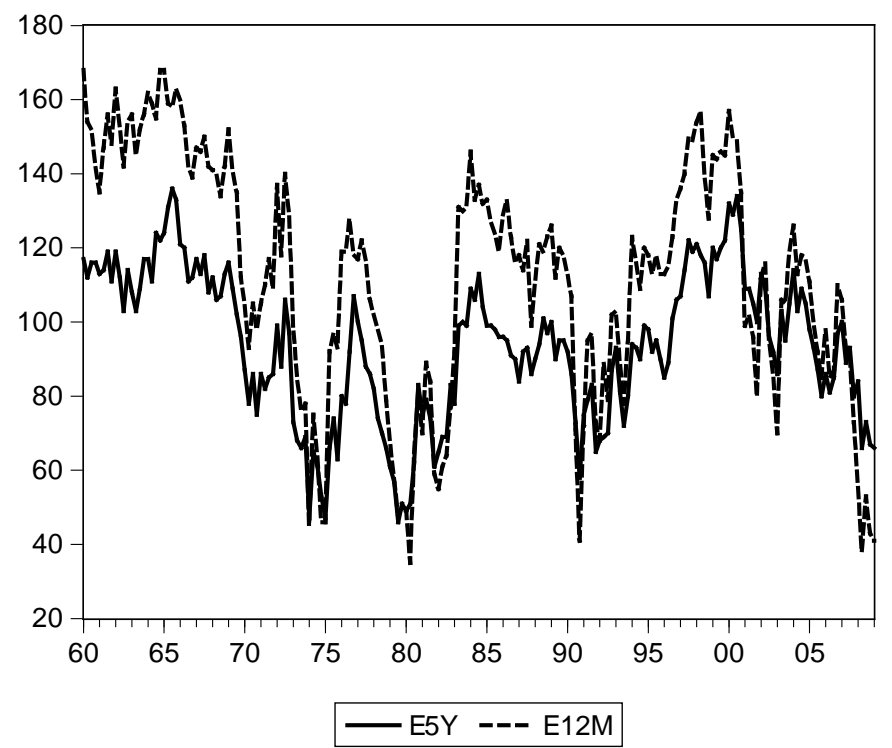

Note: The above is a time series plot of E5Y and E12M over time. E5Y is the solid line; E12M is the dashed line.

Figure 2: Impulse Responses to E5Y Innovations (ordered first)
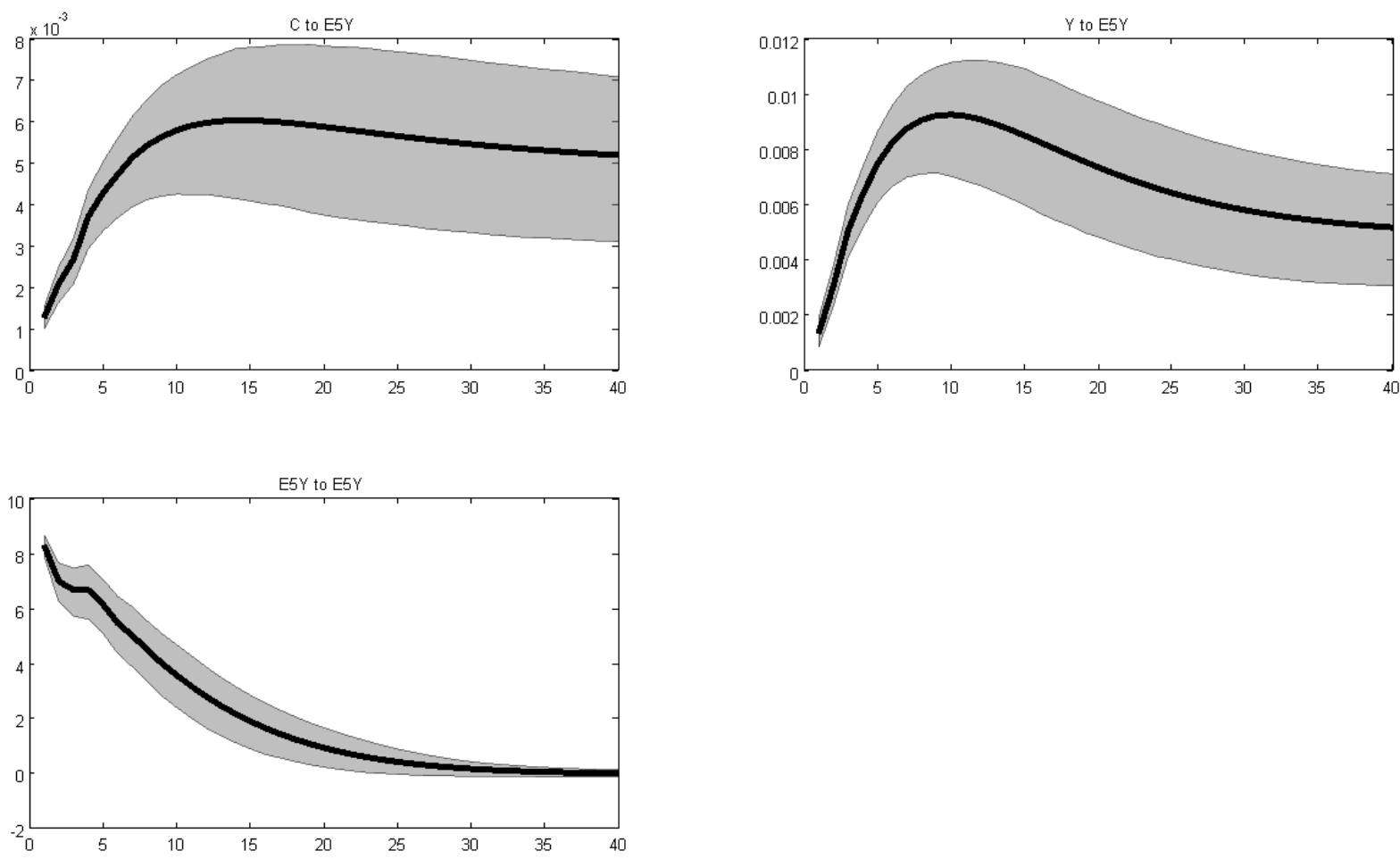

Note: These are impulse responses from a three variable VAR with E5Y, consumption, and GDP. The system features 4 lags. E5Y is ordered first. The shaded areas are one standard error bootstrap confidence bands. 
Figure 3: Impulse Responses to E5Y ordered last:
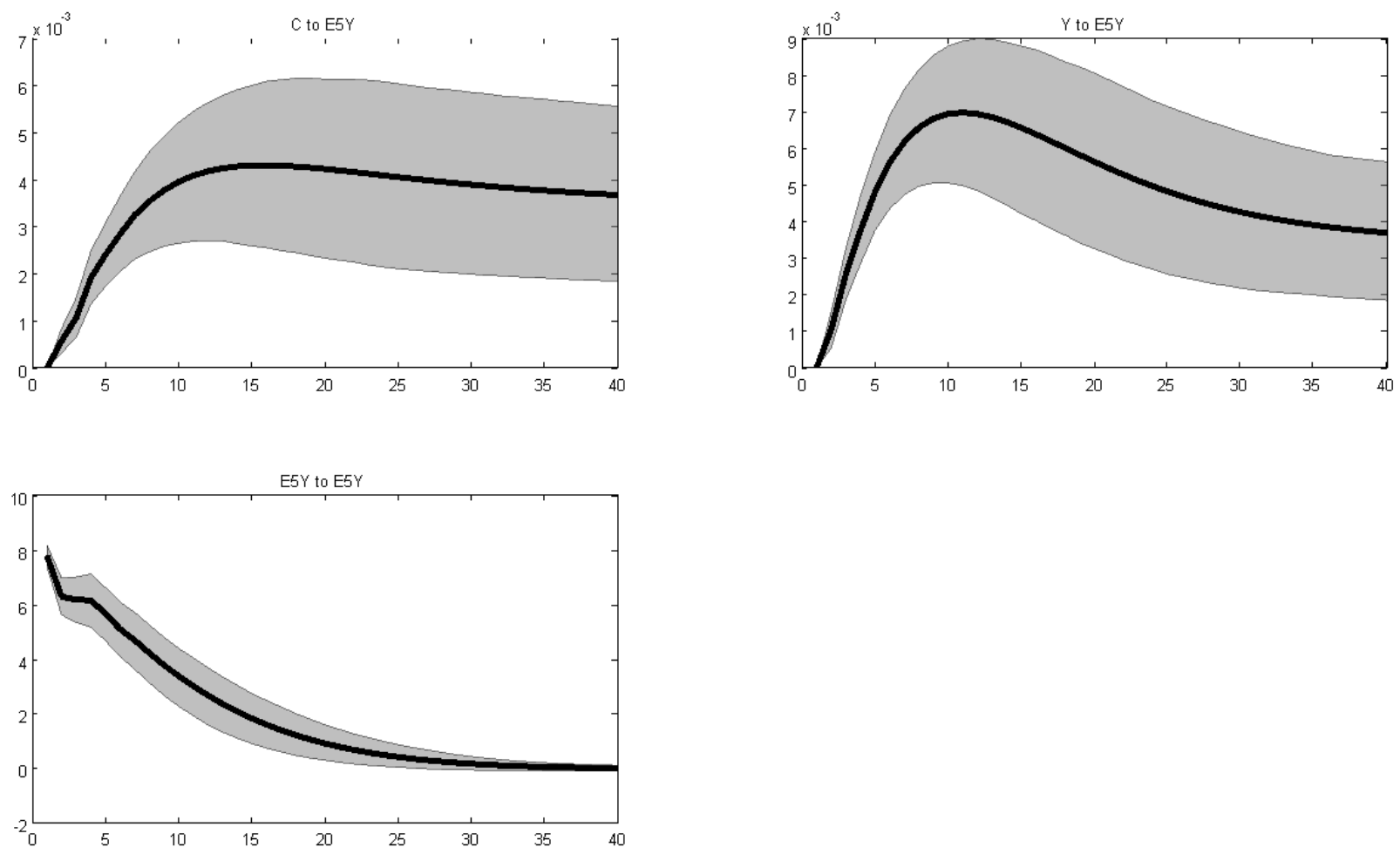

Note: These are IRFs from a three variable VAR with E5Y, consumption, and GDP. The system features 4 lags. E5Y is ordered last. The shaded areas are one standard error bootstrap confidence bands. 
Figure 4: Variance Decomposition in Three Variable VAR
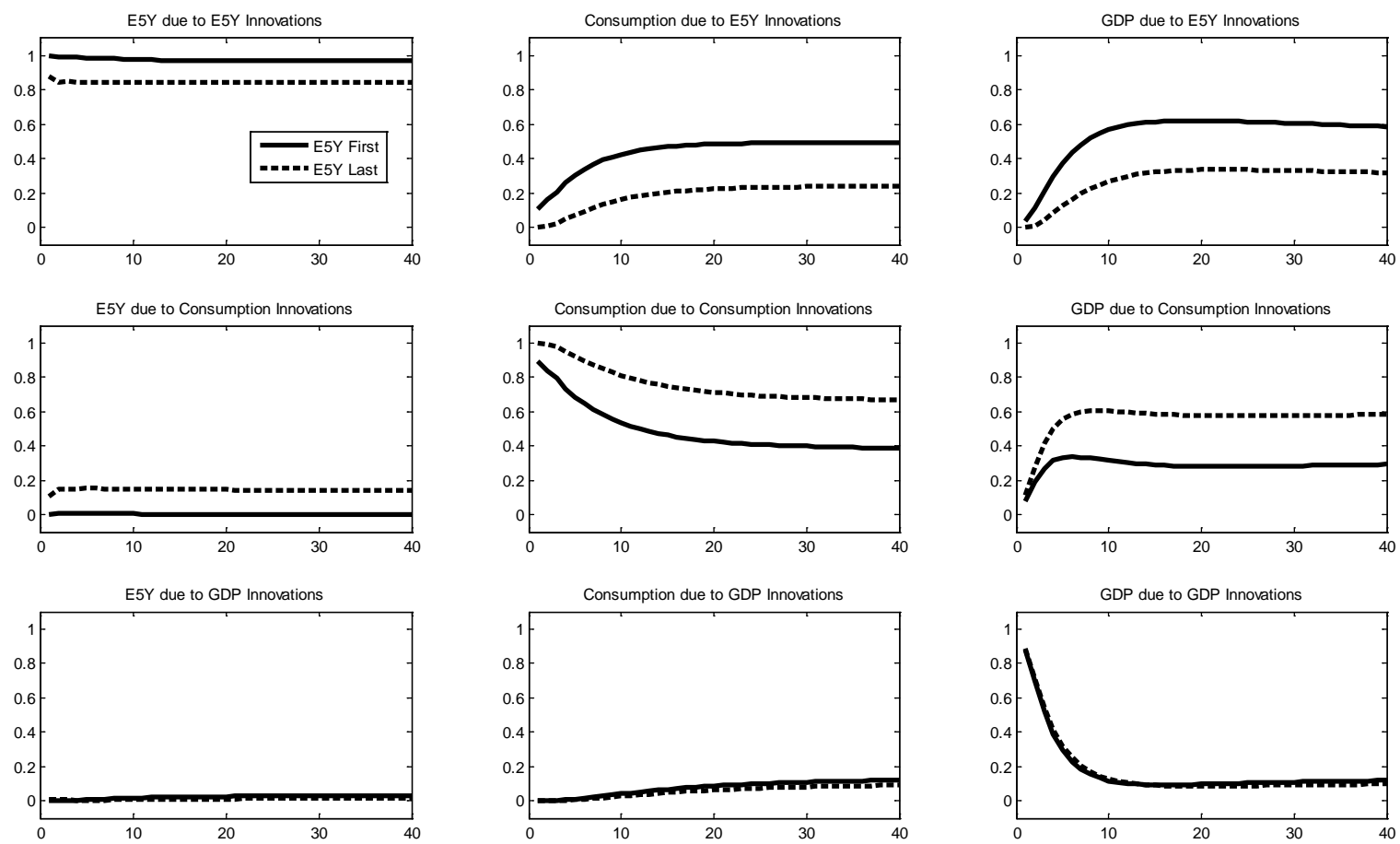

Note: These are variance decompositions from the three variable VARs whose IRFs are shown in Figures 2 and 3. The solid lines show the case in which E5Y is ordered first; the dashed lines when E5Y is last.

Figure 5: Three Variable VARs with Other Confidence Measures
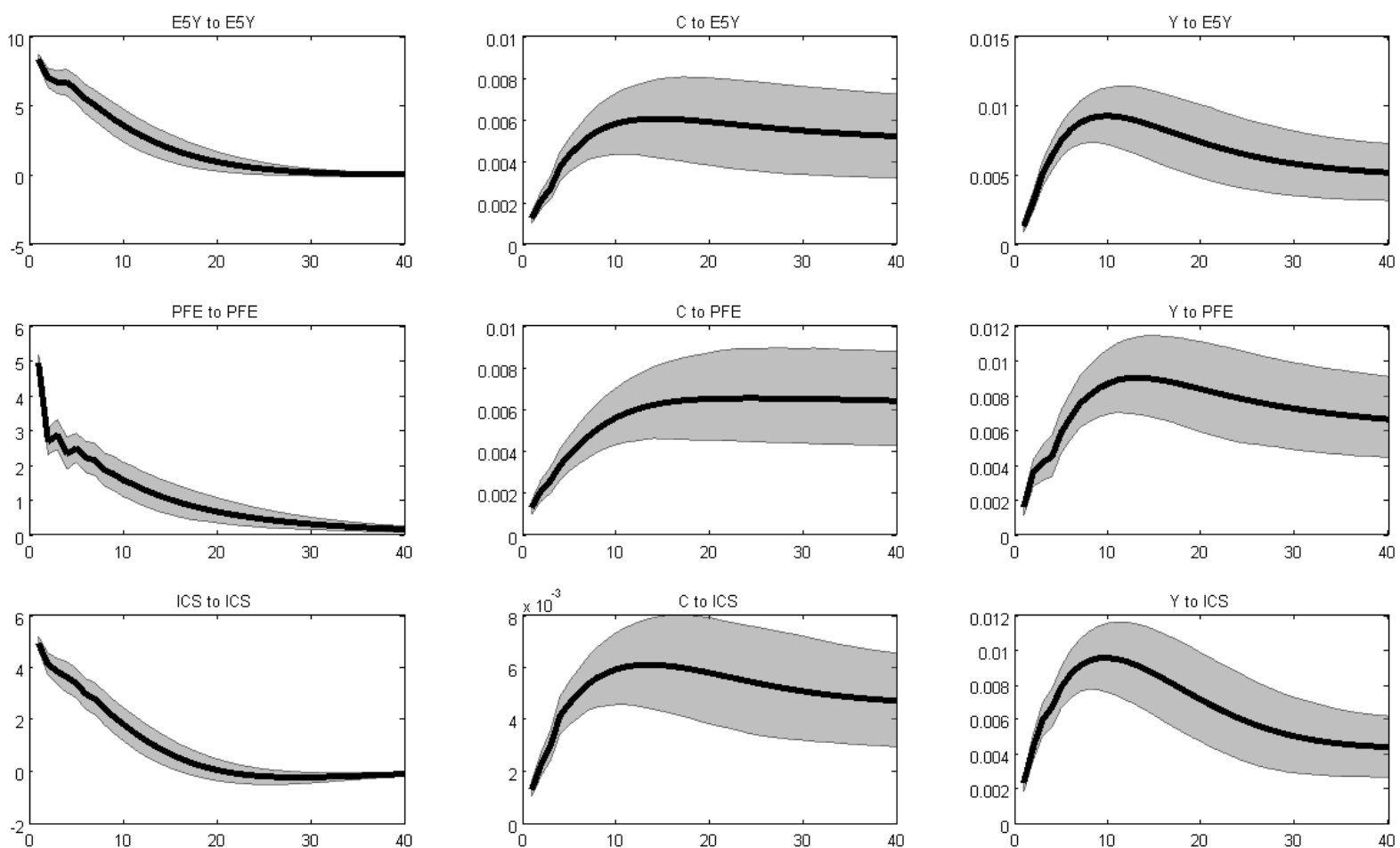

Note: These are IRFs with the confidence variable ordered first. 
Figure 6: Actual and Perceived Growth Rates:
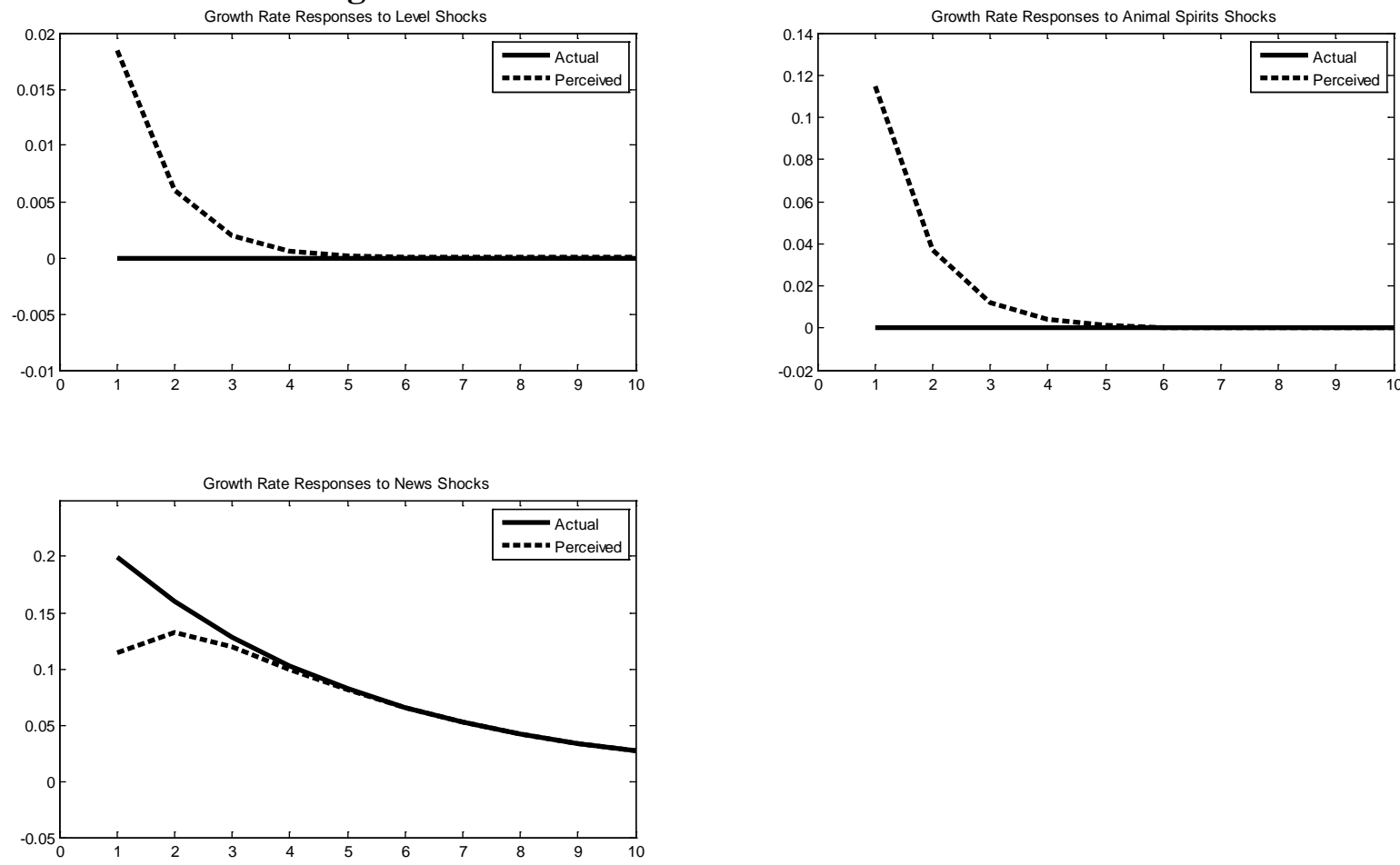

Note: These are theoretical IRFs of true and household perceived variables in the model of Section 3 to various structural shocks.

Figure 7: Impulse Responses from Larger VAR:
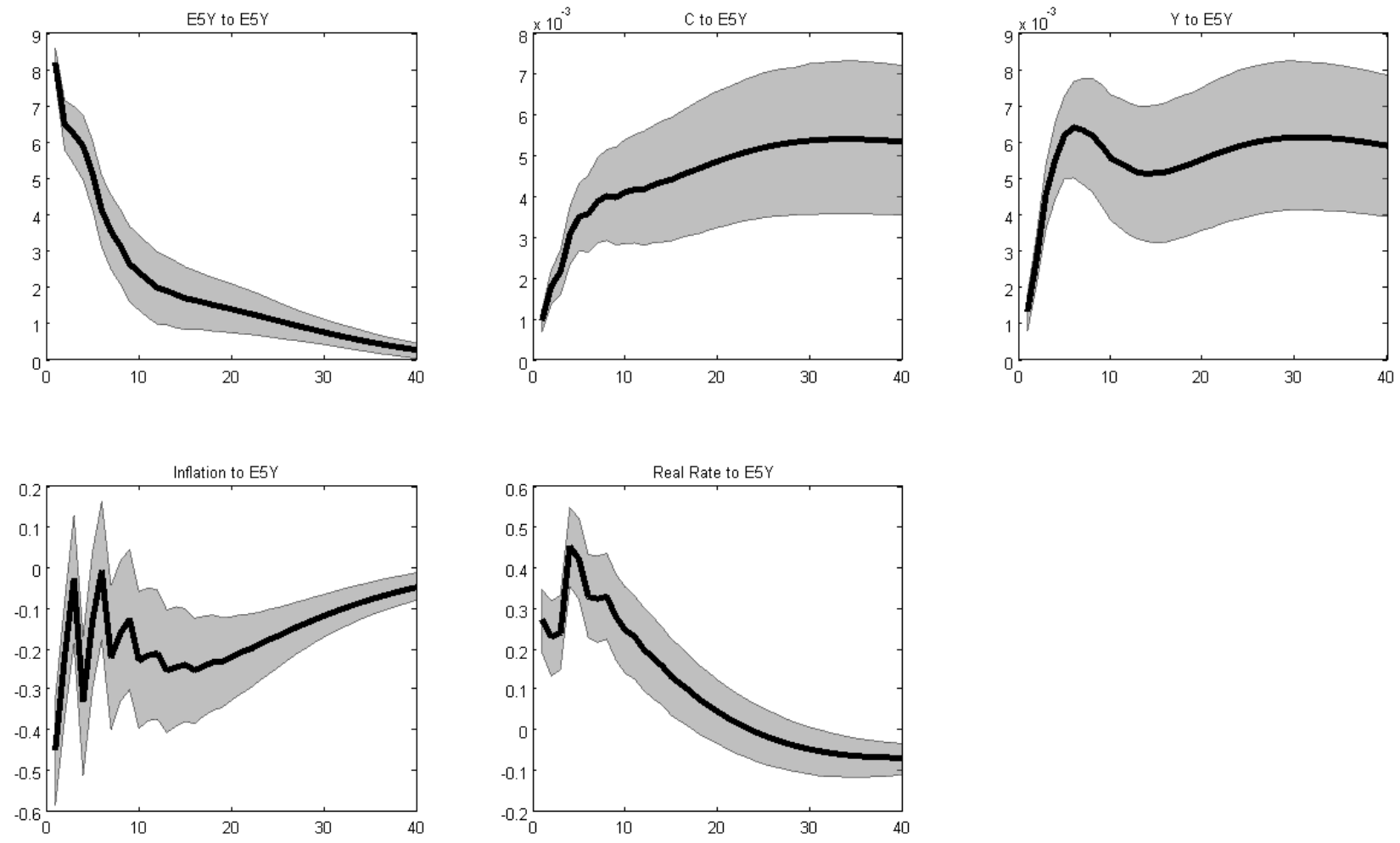

Note: These are responses from a five variable system with E5Y, consumption, GDP, inflation, and the real interest rate, with E5Y ordered first. See also the note below Figure 3. 
Figure 8: Impulse Responses to Confidence from Estimated Model:
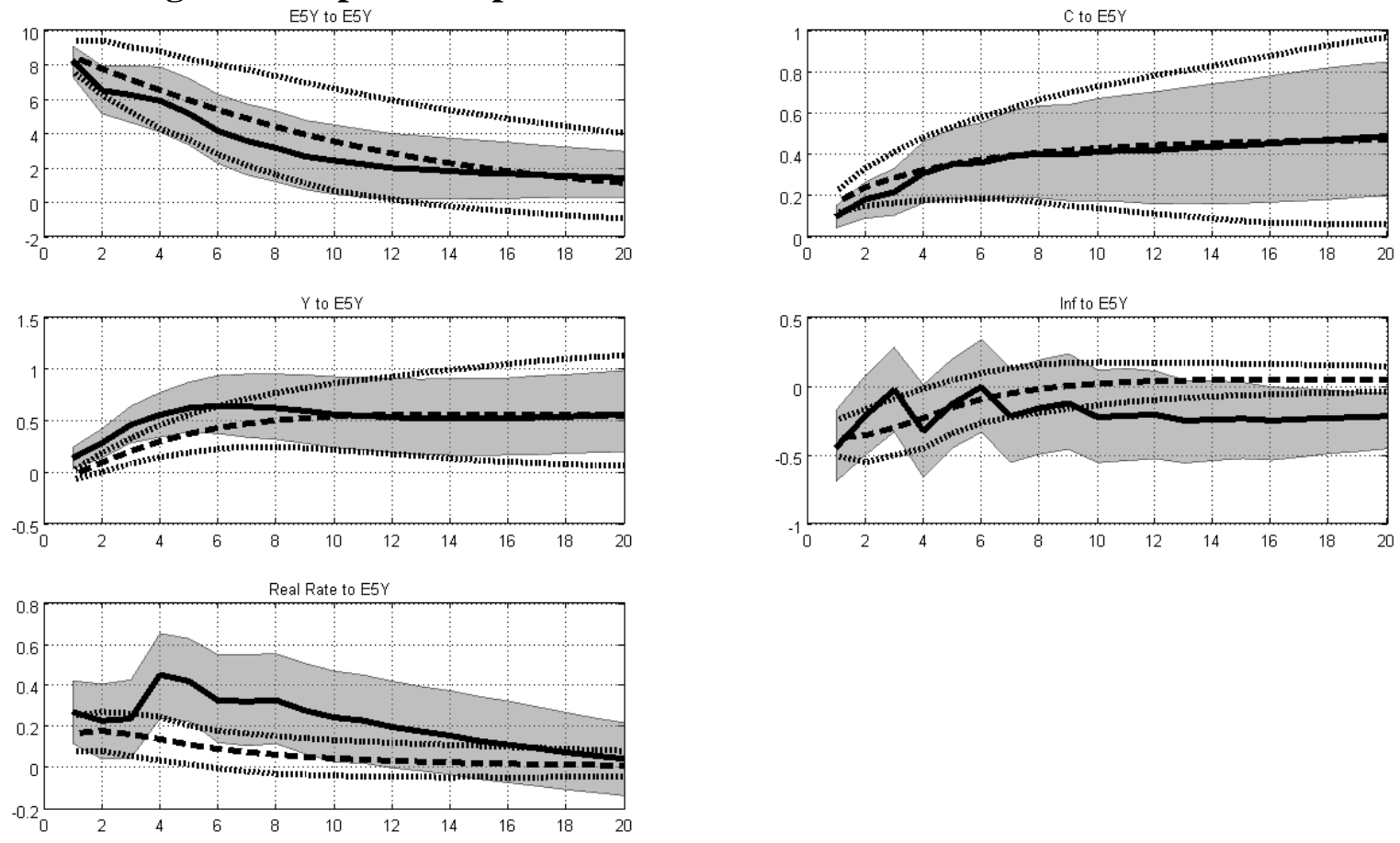

Note: The solid line is identical to the responses shown in Figure 7. The shaded gray area is the two standard error empirical confidence band. The dashed line is the average estimated response from simulations of the model at the estimated parameter values. The dotted lines correspond to the 2.5 and 97.5 percentiles of the simulated responses. The units are points for confidence and percentage points for the other variables.

Figure 9: Selected Theoretical Responses to Shocks in Estimated Model:
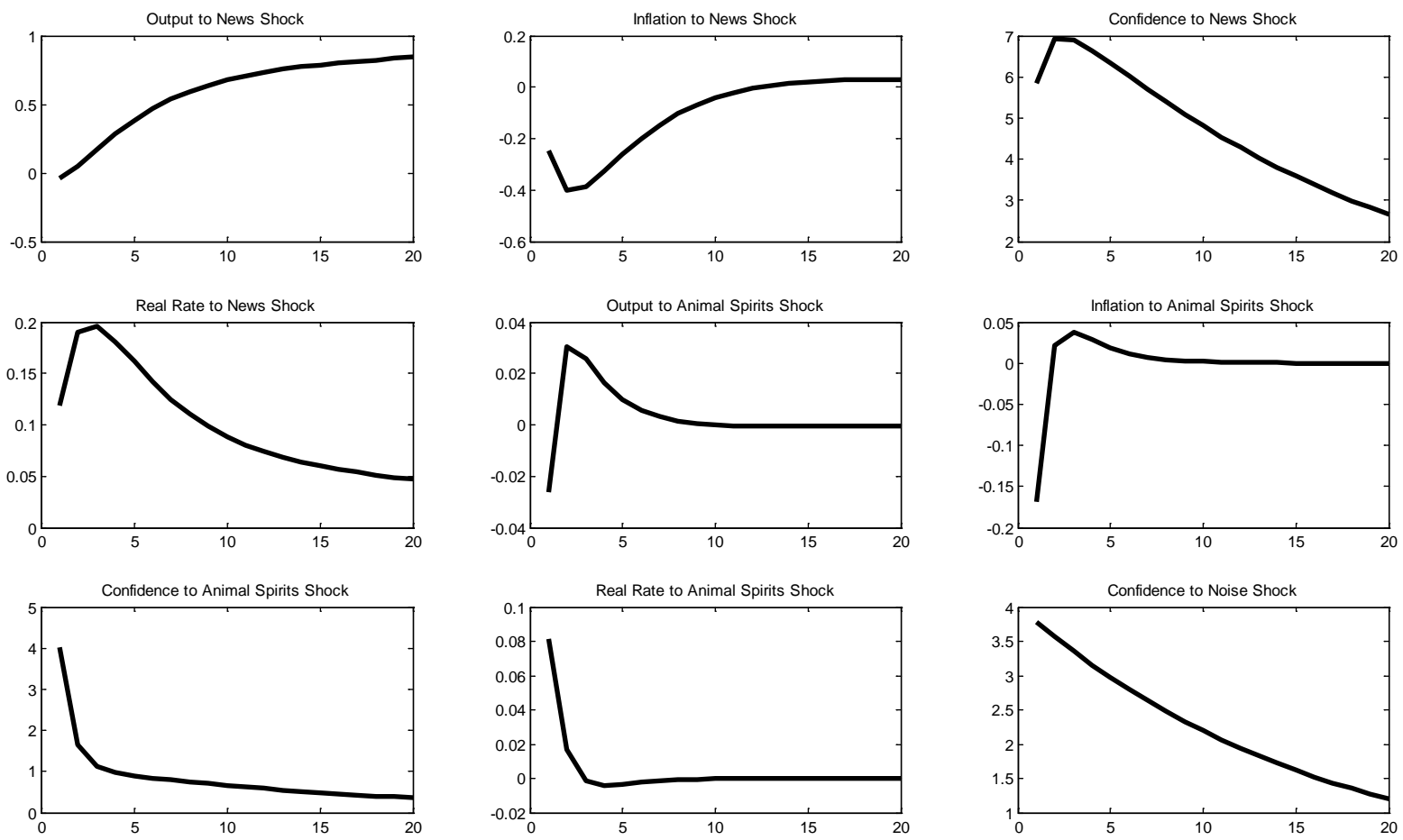

Note: these are theoretical IRFs in the model at the estimated parameter values to selected one standard deviation shocks. The responses of the non-confidence series are scaled in percentage point terms. 
Figure 10: Simulated Time Paths of Confidence:

(a) Component due to news

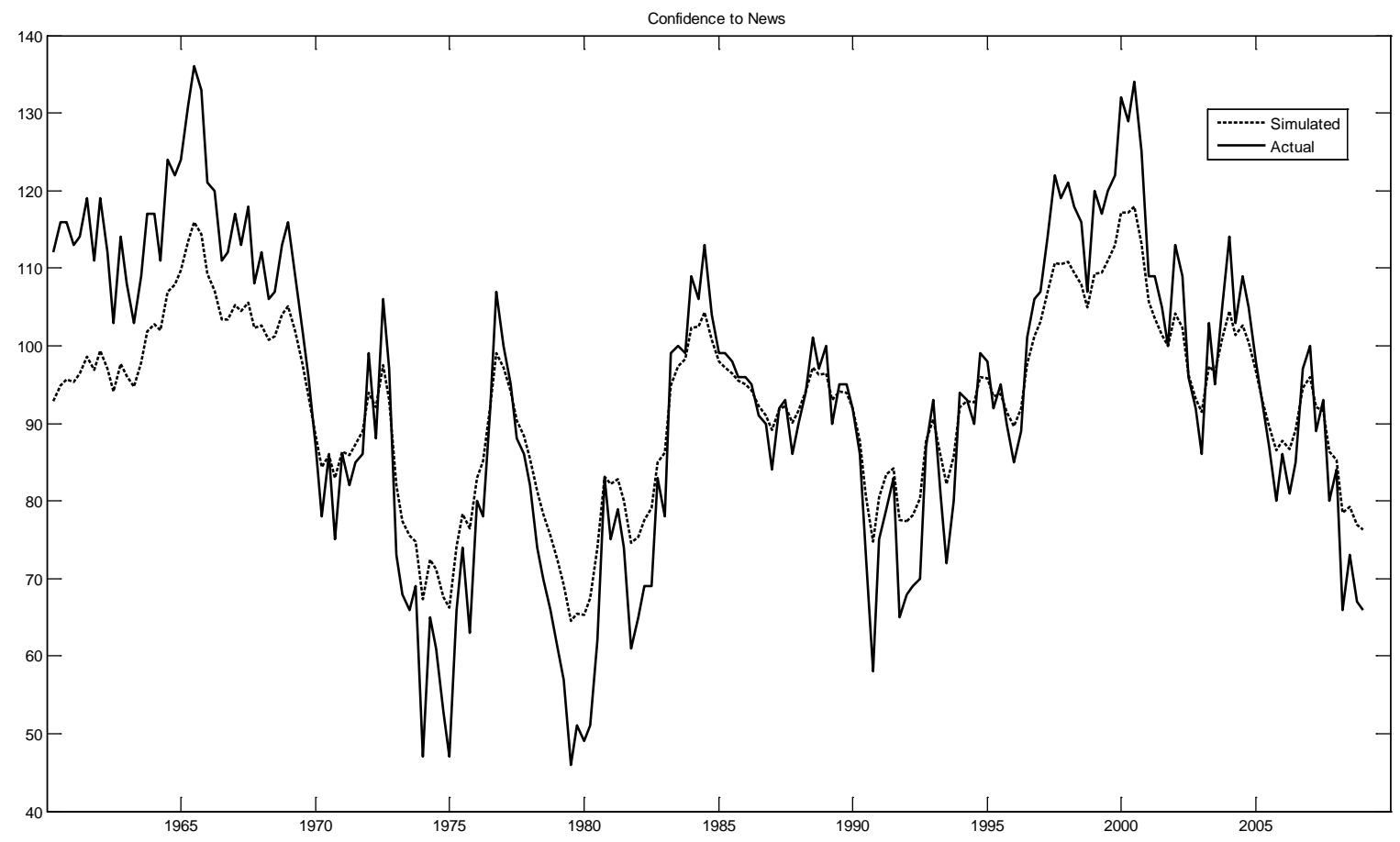

(b) Component due to animal spirits

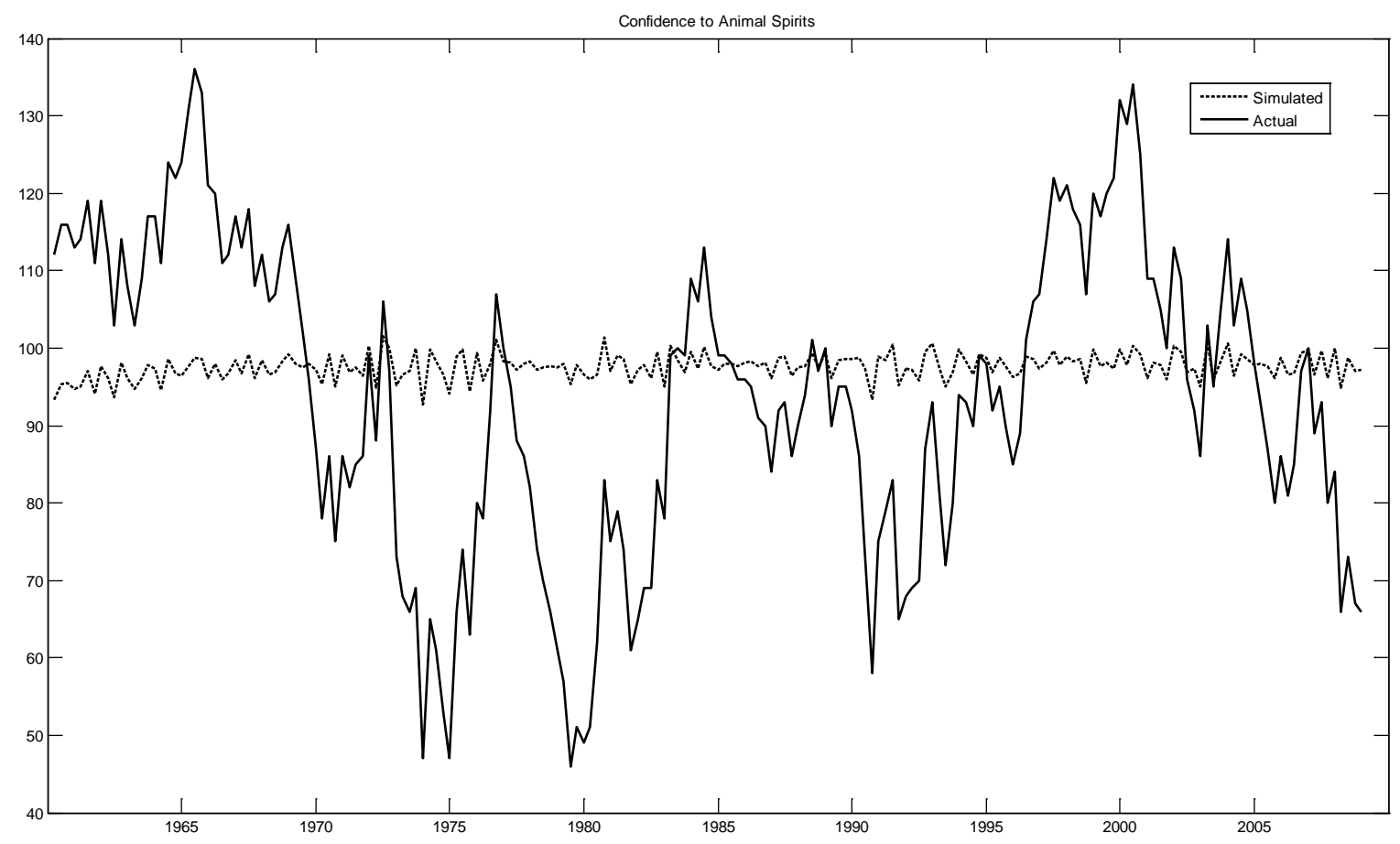


(c) Component due to level shocks:

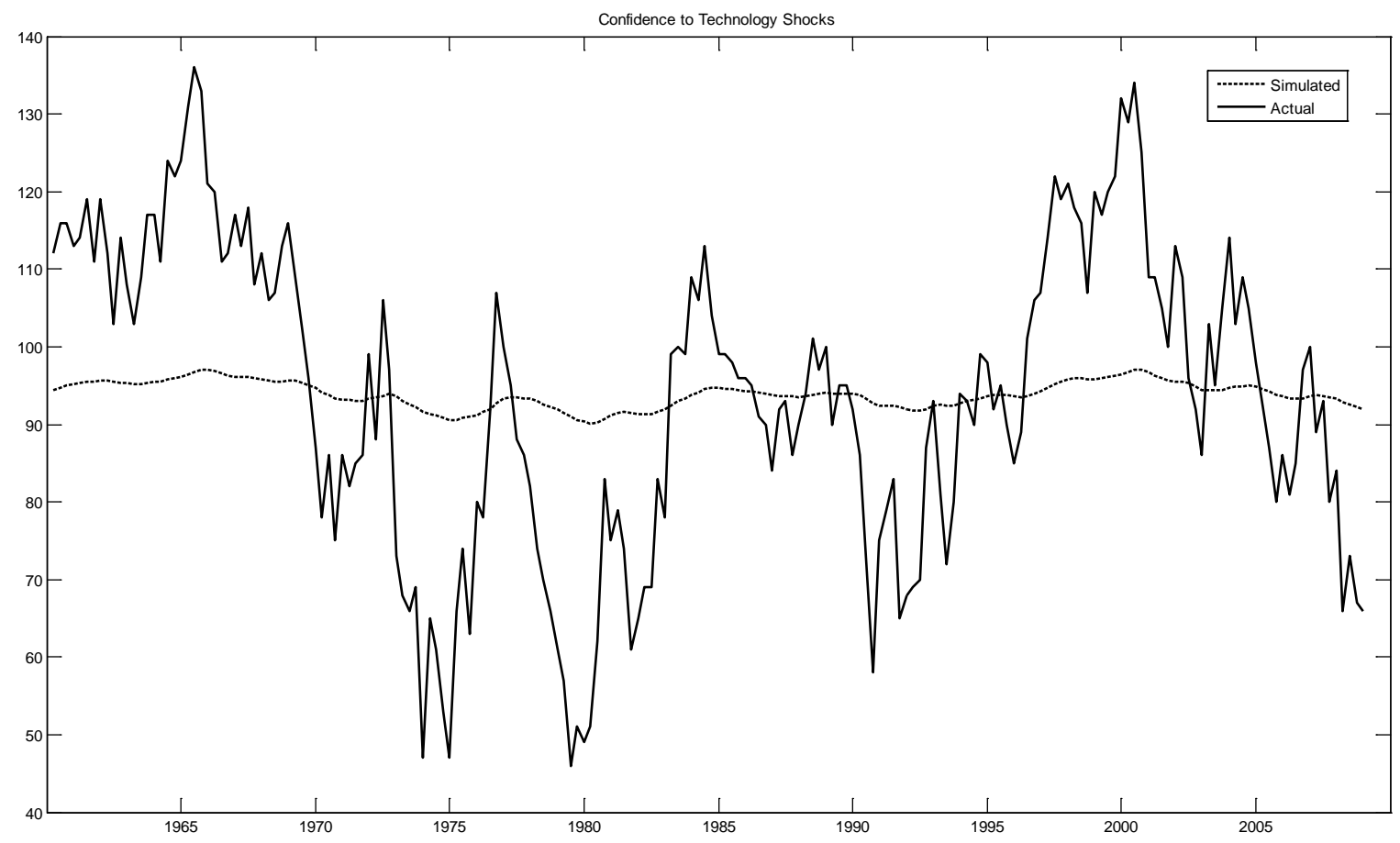

(d) Component due to noise:

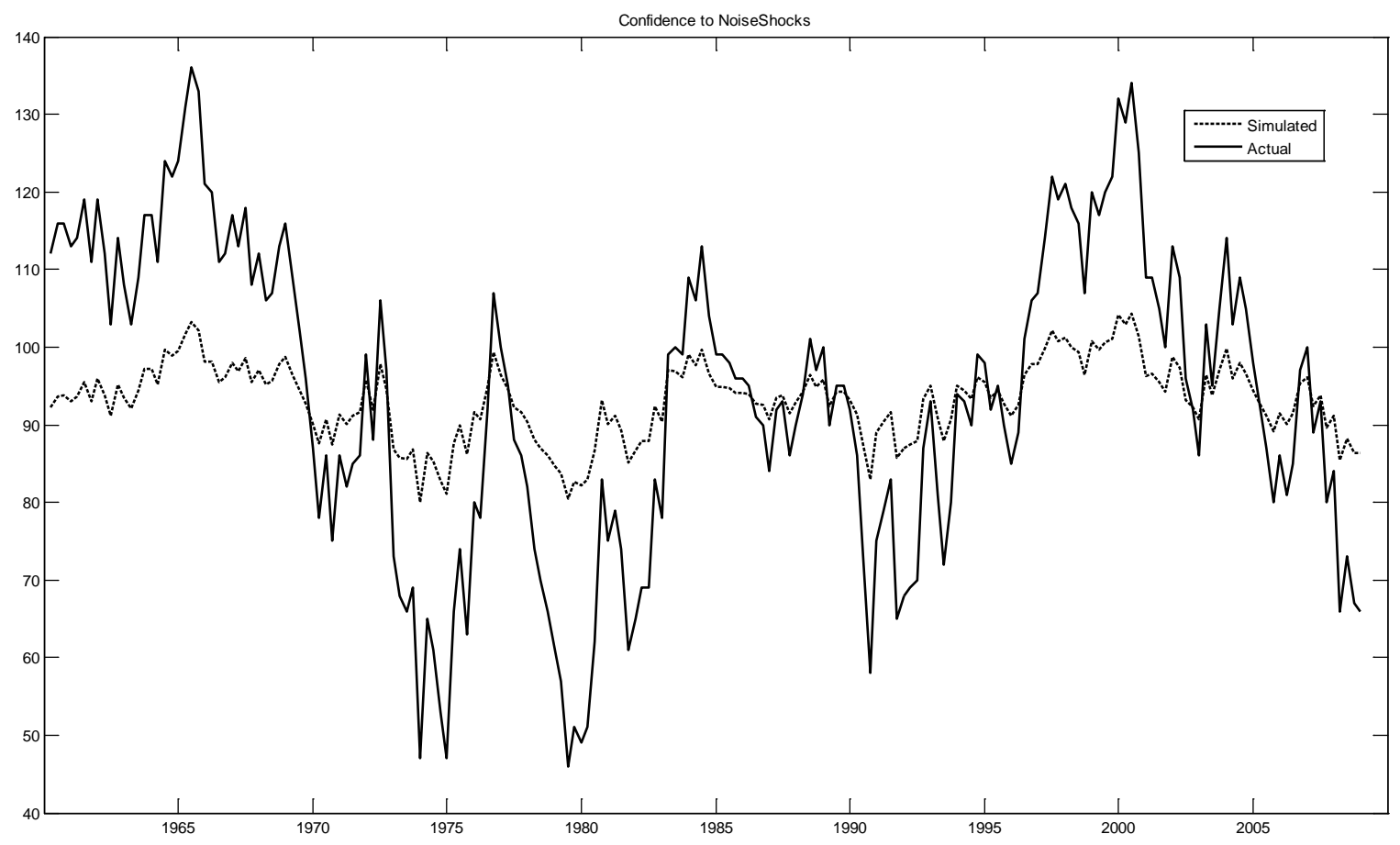

Note: The solid line shows the actual time path of E5Y; the dashed line shows the simulated time path as if the respective shock were the only stochastic disturbance in the model. 
Figure 11: Trend Productivity Growth and Confidence

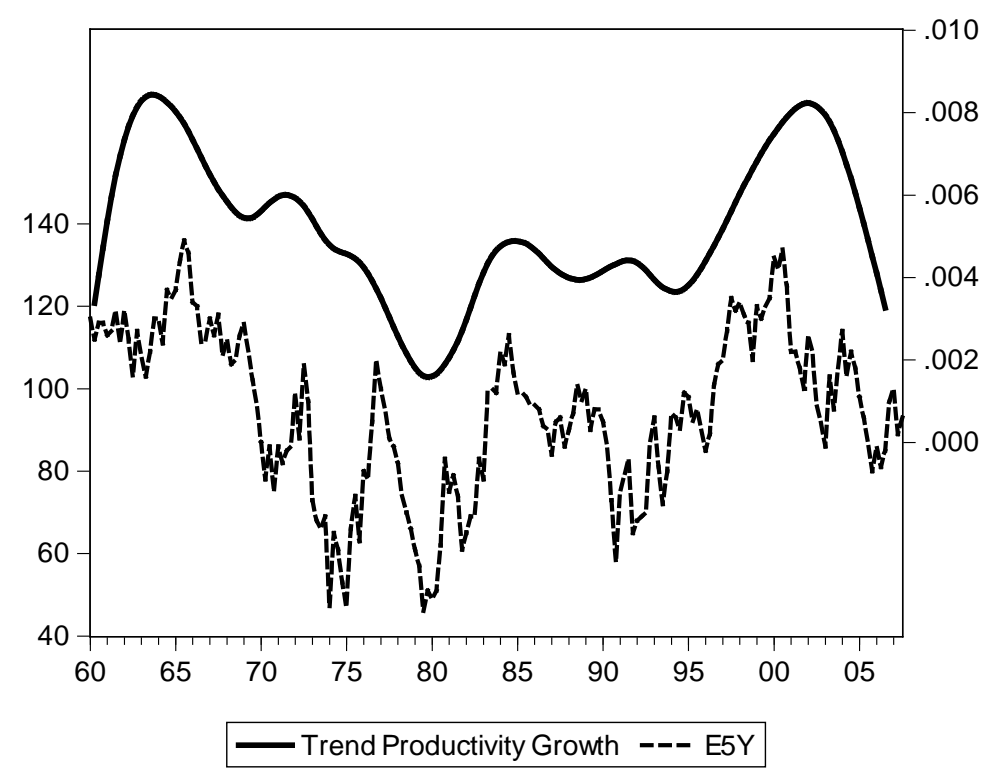

Note: This is a plot of the HP trend (smoothing parameter 1600) growth rate of output per hour and E5Y.

Figure 12: Model Response of Output to Animal Spirits Shock under "Favorable" Parameters
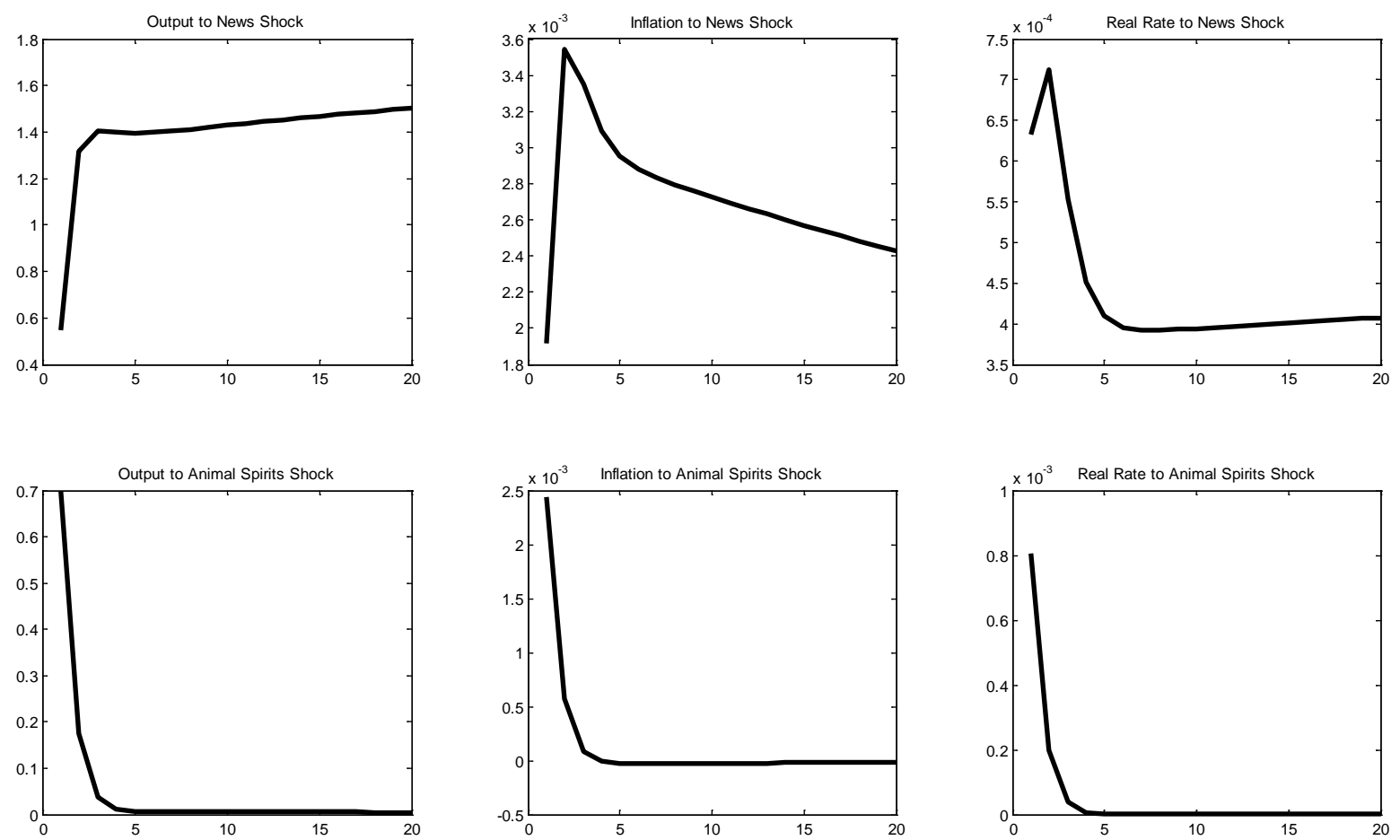

Note: This shows the theoretical IRF from the model of Section 3 at parameter values chosen to give animal spirits shocks the largest real effects. Note that the units on the inflation and real rate responses are such that these responses are less than 0.003 percentage points at per annum rates - in other words, essentially zero. 


\section{Figure 13: Responses to Confidence Innovation under "favorable” parameters}
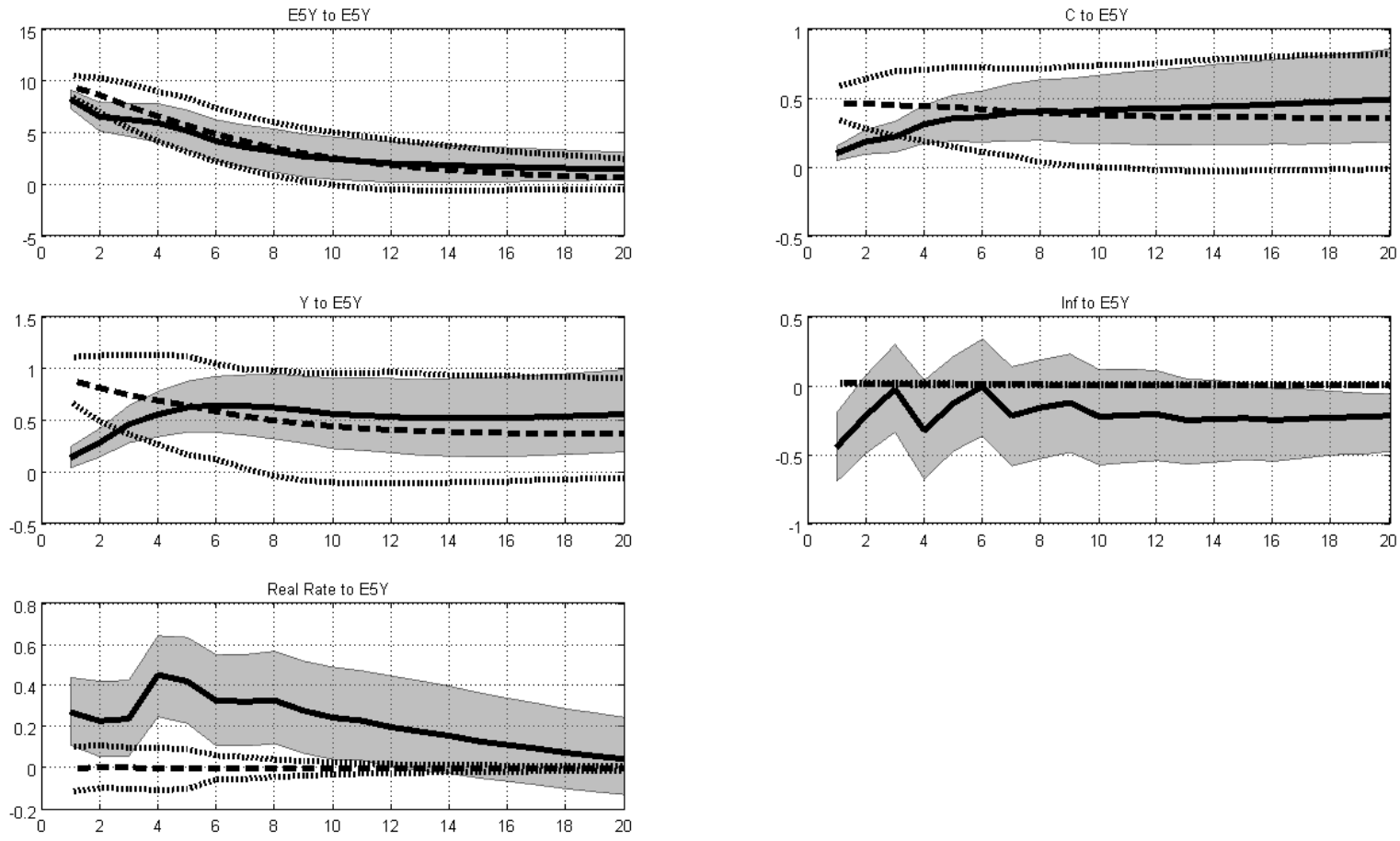

Note: This figure is similar to 8, but instead of generating the model simulated responses at the estimated parameters, the model simulated responses are computed using a parameter configuration in which animal spirits shocks can have large real effects. 
Figure 14

Spike Plots of Responses in News Heard Categories
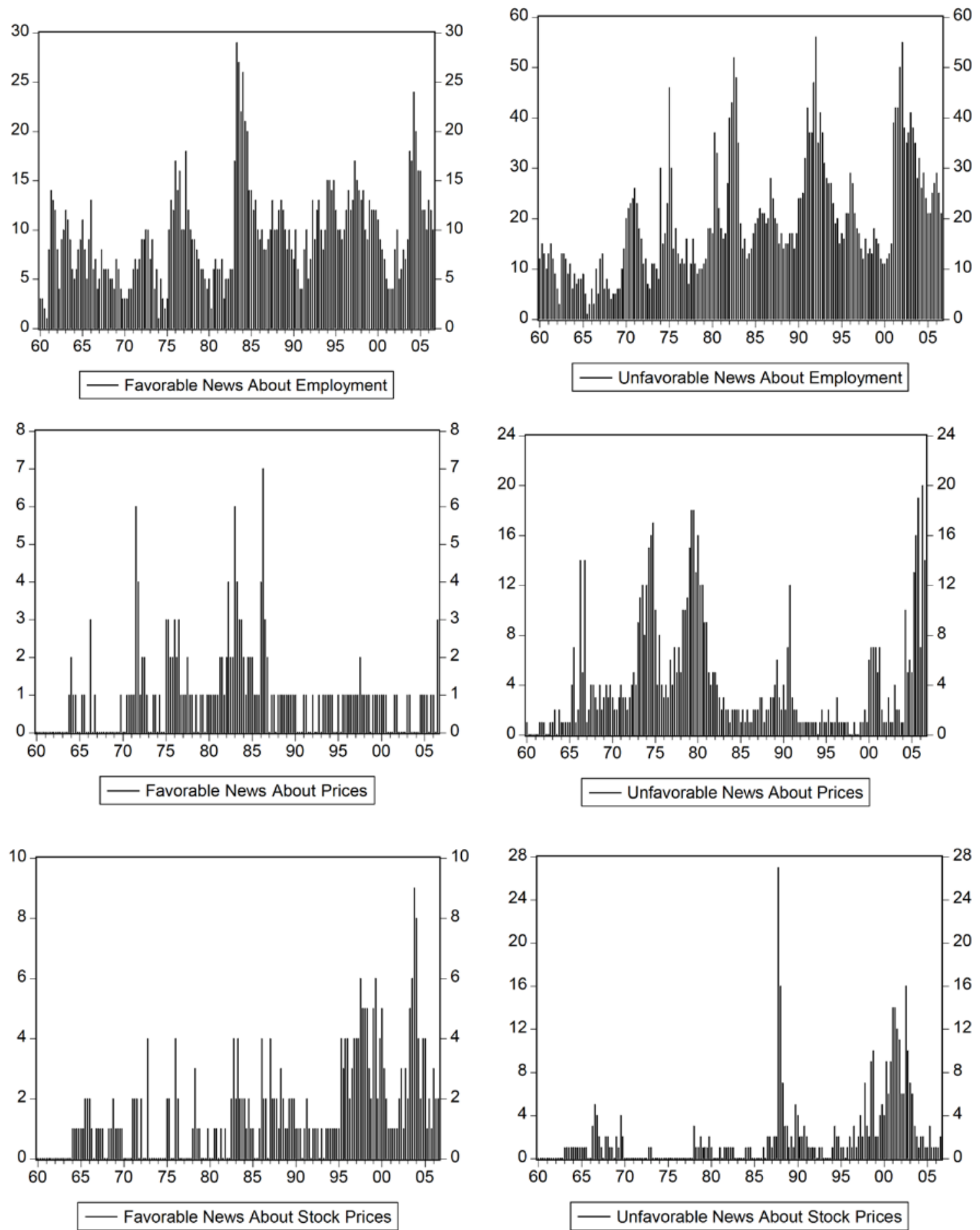

Note: These figures show the fraction of survey respondents reporting having heard news in each category in the relevant quarter. 